\title{
Gestión del proceso de inclusión de la población infantil con necesidades educativas especiales, en cuatro jardines de niños independientes
}

\author{
Process management people including children with special needs, in four gardens of children independent
}

Recibido 02 mayo 2013 • Aceptado 14 junio 2013 • Corregido 22 junio 2013

\author{
Kattya Gómez Coto' \\ Ministerio de Educación Pública \\ San José, Costa Rica \\ ninakatty_25@hotmail.com
}

\begin{abstract}
Resumen. El presente artículo corresponde a una investigación sobre la gestión del proceso de inclusión de la población infantil con necesidades educativas especiales, en cuatro jardines de niños independientes en Costa Rica. Para la investigación se tomaron como base los siguientes objetivos: Analizar el proceso que realiza la gestión del centro educativo, en relación a la inclusión de niños con Necesidades Educativas Especiales, en los grupos regulares de Educación Preescolar y Diseñar una propuesta con estrategias de intervención y mediación, para supervisar la inclusión de los niños y niñas en los grupos regulares de Educación Preescolar.

Es un estudio cuantitativo descriptivo, en el que se resaltan como principales hallazgos la necesidad de la gestión de los centros educativos en estudio de contar con diversas estrategias de supervisión en el proceso de inclusión de la población con necesidades educativas especiales a los centros infantiles, así como reconocer diversos criterios para seleccionar al personal idóneo para trabajar con la población con necesidades educativas especiales. Finalizando el estudio con una propuesta de intervención donde el gestor en su rol de supervisor reconozca las necesidades institucionales y los plasme en el plan operacional para cumplir con el derecho que la población infantil con necesidades educativas posee.
\end{abstract}

Palabras clave. Educación, administración de la educación, gestión educativa, inclusión en la educación, supervisión, perfil del docente de educación preescolar, perfil del docente en educación especial, estrategias de intervención.

\footnotetext{
Máster en Ciencias de la Educación con énfasis en Administración Educativa de la Universidad de Costa Rica (UCR). Licenciada en Ciencias de la Educación con énfasis en Administración de la Educación de la Universidad de Costa Rica (UCR). Posee el Diplomado y Bachiller en Ciencias de la Educación con concentración en Preescolar de la Universidad Nacional (UNA). Licenciada en Ciencias de la Educación Preescolar de la Universidad Latina. Actualmente labora como docente de educación preescolar para el Ministerio de Educación Pública (MEP), en el Jardín de Niños Ascensión Esquivel, Cartago, Costa Rica. Ha sido docente de I Ciclo de la Educación General Básica en la Escuela Jesús Jiménez Zamora y asistente de supervisión, ambos para el Ministerio de Educación Pública (MEP).
} 
Abstract. This article corresponds to a research of the management on the inclusion process of children with special educational needs in four independent kinder gardens. For the investigation were taken as base the following objectives: To analyze the process that manages the school, in relation to the inclusion of children with special educational needs, in regular groups of preschool education and to design a proposal with intervention strategies and mediation, to supervise the inclusion of children in regular groups of preschool education.

The methodology used for the study is quantitative descriptive. The conclusions obtained highlight the need for management in the schools in the study of having diverse supervision strategies in the process of inclusion of children with special educational needs in childcare centers as well as recognize various criteria to select suitable personnel for working with children with special educational needs. Completing the study with a proposal for intervention where the manager in his role of supervisor recognizes the institutional needs and translate them into the operational plan to meet the rights of children with special educational needs.

Keywords. Education, educational administration, educational management, inclusion in education, supervision, preschool teacher profile, special education teacher profile, intervention strategies.

\section{Introducción}

El interés primordial de la investigación realizada es, en primera instancia, hacer conciencia tanto en los gestores y gestoras de la educación como en el personal docente sobre la importancia de promover la inclusión de los niños y niñas con necesidades educativas especiales, en los centros educativos del país, iniciando desde la etapa preescolar. Promoción que hacen diversos organismos internaciones como el Fondo de Naciones Unidas para la Infancia (UNICEF) y la Organización de las Naciones Unidas para la Educación, la Ciencia y la Cultura (UNESCO), quienes reiteran el compromiso con la población infantil con necesidades educativas especiales de un trato más personalizado y acorde con sus requerimientos para que puedan acceder a una educación iniciando desde el Preescolar, donde se le faciliten las condiciones para el óptimo desarrollo para una vida plena y digna, en todos los niveles, independientemente de su condición social, económica, étnica, de género o discapacidad.

La educación como derecho humano permite a las personas ejercerlo, por tanto, nadie puede quedar excluido de ella. El derecho a la educación se ejerce en la medida en que las personas alcancen a desarrollarse plenamente y continúen su aprendizaje; esto significa que la educación ha de ser de calidad para todos, a lo largo de la vida.

La convención sobre los Derechos del Niño de la UNICEF (1989), afirma lo anterior al acordar que todos los derechos incluidos en la convención, deben aplicarse a toda la población infantil sin excepción alguna. Por tanto, es obligación de los Estados tomar las medidas que sean necesarias para proteger a los niños y niñas de cualquier tipo de discriminación; a la vez de estipular pautas en materia de atención de la salud, la educación y la prestación de servicios jurídicos, civiles y sociales. 
En efecto, Richmond (2009) plantea que a través de la historia "la Educación Especial ha evidenciado el esfuerzo reiterado de padres, madres y profesionales por la reivindicación de los derechos de las personas con discapacidad" (p.82). En el ámbito nacional no se debe dejar de lado la promulgación de la Ley de Igualdad de Oportunidades para las personas Discapacitadas (1996), Ley 7600, la cual garantiza el acceso oportuno a la educación de las personas, independientemente de su discapacidad, desde la estimulación temprana hasta la educación superior, siendo el Estado el que vele por que se cumpla.

Por tanto, la investigación propone conocer el rol del gestor y gestora en el proceso de inclusión de la población infantil con necesidades educativas especiales a los jardines de niños y con el aporte de los docentes, verificar lo que necesitan para que se dé un verdadero proceso de inclusión.

Ante ello, el gestor y gestora de los centros educativos debe ser una persona anuente al cambio, innovador e innovadora, que atienda al cumplimiento de la Ley 7600 (1996) que en materia de inclusión rigen su actuar, consciente de identificar las modificaciones que a lo interno de la organización educativa se deben realizar, las cuales van desde el aspecto de infraestructura como el dotar de materiales, reorganizar y modificar los diversos espacios de las aulas, así como liderar un verdadero cambio en el currículum y trabajo con los y las docentes, para atender las necesidades y demandas educativas de la población con necesidades educativas especiales. específicos:

El trabajo de investigación se fundamenta en los siguientes objetivos generales y

\section{Objetivos generales}

1. Analizar el proceso que realiza la gestión del centro educativo, en relación con la inclusión de la población infantil con necesidades educativas especiales, en los grupos regulares de educación preescolar, de los jardines de niños independientes Ascensión Esquivel, Jesús Jiménez, República Francesa y Ricardo Jiménez Oreamuno.

2. Diseñar una propuesta con estrategias de intervención y mediación, para supervisar la inclusión de la población infantil en los grupos regulares de educación preescolar.

\section{Objetivos específicos}

1.1 Determinar en el plan operativo institucional las estrategias de supervisión que realiza la gestión del centro educativo, en relación con el proceso de inclusión de la población infantil con necesidades educativas especiales, en los grupos regulares de educación 
preescolar.

1.2 Identificar los criterios de selección de personal que utiliza la gestión del centro educativo, para asignar los docentes para atender a la población infantil con necesidades educativas especiales, en los grupos regulares de educación preescolar.

1.3 Describir el proceso realizado por la gestión del centro educativo, al implementar las estrategias de intervención en el proceso de inclusión de la población infantil con necesidades educativas especiales, en los grupos regulares de educación preescolar.

2.1 Diseñar una propuesta de gestión del centro educativo con estrategias de intervención y de mediación, para supervisar el proceso de inclusión de la población infantil en los grupos regulares de educación preescolar.

\section{Marco teórico}

\section{Gestión educativa.}

La educación como pilar fundamental de la sociedad costarricense requiere de gestores y gestoras educativos comprometidos, responsables de hacerla efectiva, ofreciendo una educación de calidad, acorde con las demandas sociales, las cuales deben responder a las necesidades de igualdad y equidad entre las personas.

En efecto, la gestión educativa no es un nombre nuevo para la administración, ni para la planificación, como indican Pozner, Ravela y Fernández (2000):

Sólo puede ser entendida como nueva forma de comprender y conducir la organización escolar, en la medida en que se reconozca como uno de sus fundamentos el cálculo estratégico situacional; y más aún, sólo en la medida en que éste proceda, presida y acompañe esa acción educativa de tal modo que, en la labor de la enseñanza, llegue a ser un proceso práctico generador de decisiones y comunicaciones específicas. (pp. 16-17)

A la vez, gestión tiene ver con asumir retos, con la revisión del concepto de organizaciones cerradas, por abiertas, con innovación, cambio, manejo de la incertidumbre, las tensiones, las ambigüedades y conflictos. Para enfrentar tales problemáticas, los gestores y gestoras necesitan contar con diversas capacidades para generar proyectos compartidos, redes de alianzas entre los diferentes entes sociales que apoyan las organizaciones y capacidad para liderar. Como mencionan Pozner et al. (2000), las organizaciones educativas requieren de"gestores estratégicos con espíritu de prospectiva, de reconocer demandas sociales, de generar participación y acuerdos; con potencia para ordenar e interpretar el caos de datos e informaciones, utilizando 
analogías, modelos o metáforas" (p. 20).

Por tanto, a la gestión educativa le corresponde originar una diversidad de estrategias que promuevan numerosas soluciones a los procesos de enseñanza, en otras palabras, implementar nuevas prácticas, experimentar nuevos métodos y técnicas, enfatizando en el aprendizaje constante, la renovación y actualización de conocimientos, mediante la capacitación, los asesoramientos, el trabajo en círculos de estudio, se necesitan profesionales más competitivos y proactivos.

En este orden de ideas, se puede mencionar a Machado citado por Castillero, Díaz, Morales y Pino de Ochoa (2009), quien indica que para el éxito escolar algunos de los roles del gestor o gestora educativo son:

- Preocupación por la capacitación de los docentes con el fin de mejorar su desempeño y trabajo en equipo.

- Intercambiar información con los diferentes niveles de la administración: profesores, estudiantes, padres de familia y el resto de la comunidad.

- Establecer políticas bien definidas y con metas claras. Esto en conjunto con profesores y miembros de la comunidad.

- Interactuar con la comunidad escolar y la comunidad local abriendo la escuela a la participación.

- Hacer efectiva la entrega del currículo básico, así como definir y desarrollar las adaptaciones que correspondan de acuerdo con los intereses específicos de la comunidad local. (p. 54)

Es evidente entonces, que el rol de la gestión educativa en la conducción de organizaciones actuales, como lo indican Pozner et al. (2000), será el de:

Generar una visión que comunique el proyecto, que despliegue sentido, pertenencia y el impulso para enfrentarse permanentemente a las metas trazadas. Y que dé lugar al desarrollo de ambientes de trabajo basados en la confianza que estimulen una"coevolución creadora" entre los sujetos, y de ellos con el entorno. (p. 22)

Cabe agregar, que la gestión educativa debe propiciar a su vez, la apertura para crear espacios de participación efectiva de los distintos actores de la comunidad y del entorno escolar, vistos como un apoyo sustantivo en la proyección futura y como recurso para responder a las demandas que la sociedad le hace.

En ese orden de ideas, se puede citar a Castillero et al. (2009), quienes mencionan que una gestión participativa es aquella que "establece instancias concretas para el intercambio de opiniones, de interacción social y de incorporación de ideas, valores, creencias, mitos e intereses de los estudiantes, docentes, padres de familia, unidades vecinales, empresarios, entre otros, en 
el quehacer escolar" (p. 14). En efecto, la gestión educativa tiene el deber de establecer relaciones e intercambio de opiniones con los padres de familia o encargados, primeros formadores, tal como indican Castillero, et al. (2009), es en el seno familiar donde:

(....) se tejen los lazos afectivos primarios, los modos de expresar el afecto, la vivencia del tiempo y, del espacio, las distancias corporales, la historia de la familia grande, extensa, que comprende a las distintas generaciones que nos precedieron, es decir, todas las dimensiones humanas más significativas se plasman y transmiten en la cotidianeidad de la vida en familia. Este es por excelencia el campo de las relaciones afectivas más profundas y constituye, por lo tanto, uno de los pilares de la identidad de una persona. (pp. 55-56)

Significa entonces que, tanto el gestor educativo como la gestora educativa, desarrollan una serie de funciones y requieren, como plantea Pozner et al. (2000) de:

- Un enfoque claro e interrelacionado,

- alta capacidad de concentración,

- conciencia de que los tiempos de gestión suponen períodos largos de gestión,

- exploración permanente de las oportunidades,

- disciplina para el aprendizaje profundo,

- confianza en sí mismo,

- saber aprender (metaconocimiento),

- saberes y prácticas de colaboración,

- capacidad de experimentar,

- gusto por el riesgo,

- sentido de responsabilidad,

- compromiso e iniciativa,

- profesionalidady

- voluntad de servicio. (p. 32)

Es evidente, que las organizaciones educativas en la sociedad del conocimiento demandan profesionales en la gestión educativa con nuevas capacidades y competencias, donde se coordinen y articulen las distintas acciones planificadas por su equipo de trabajo en busca de hacer del centro educativo, una organización que posibilite la consecución de la intencionalidad pedagógica, a través de un proceso de participación efectivo de toda la comunidad escolar.

Cabe agregar que el gestor educativo y la gestora educativa tienen que aprender a desaprender, para ello, se deben modificar esquemas, instaurar nuevos, asumir riesgos y participar del cambio y la innovación. Según Olala citado por Contreras (2005): 
Aprender es más que recibir o acopiar información. Sugiere muy vívidamente que es un proceso en el que hay que cambiar; dejar de hacer, pensar o ser como éramos antes del proceso de aprendizaje. Implica "dejar ir" algo que antes teníamos. (p.32)

En efecto, los profesionales en gestión de la educación tienen que aprender a desaprender identificando las necesidades, revisandoy dejando ir ciertos aprendizajes previos para incorporar los nuevos. Esto se presenta por los cambios que están ocurriendo en las organizaciones educativas, que demandan de los gestores y gestoras de la educación, mayor compromiso con un servicio educativo de calidad.

\section{Inclusión en la educación.}

La educación inclusiva surge del reconocimiento de ésta como un derecho humano básico, de todos y no de unos pocos, y como un principio indispensable para el desarrollo individual y social que promueve la paz, la libertad y la justicia, en contraposición con la exclusión, la discriminación, a la ignorancia y a la guerra.

Como indica Meléndez (2005):

La inclusión tiene que ver con derechos humanos, con desarrollo, con democracia y con oportunidad de vida con calidad; $y$, tanto para alcanzarla como sostenerla, se requiere del dominio técnico y de competencia cognoscitiva por parte de todos los sectores de un país. (p. 62)

En efecto, es importante tener presente que como derecho fundamental a la educación, es deber de todos hacer valer el mismo y sobre todo, abrirles las puertas a la población infantil con necesidades educativas especiales, hacia nuevos conocimientos, nuevas metas y formas de ver la vida. Por tanto, como indica la UNESCO citada por Ávila y Esquivel (2009):

La educación inclusiva supone un impulso a la agenda de la Educación para Todos, desarrollando formas de habilitar a las escuelas para que atiendan a todos los niños y las niñas de su comunidad, como parte de un sistema inclusivo. La educación inclusiva se centra en todos los alumnos, prestando especial atención a aquellos que tradicionalmente han sido excluidos, tales como los alumnos con necesidades educativas especiales y discapacitadas, niños pertenecientes a minorías étnicas y lingüísticas, y otros. (p. 12)

En este sentido, la educación inclusiva surge como respuesta ante la necesidad de hacer cumplir el derecho universal que tiene todo ser humano de recibir educación. En el campo de la educación, el concepto de inclusión comienza a tener sentido propio, construido sobre la base de las buenas ideas para justificar y ejercer el derecho a educarse por encima de las particularidades personales y culturales. 
Como indica el Centro Nacional de Recursos para la Inclusión Educativa (CENAREC, 2004):

La inclusión educativa es un concepto mucho más amplio, ya que no se trata solo de lograr el acceso a la escuela común de determinados grupos de alumnos, tradicionalmente excluidos, sino también de transformar el sistema educativo en su conjunto para atender la diversidad de necesidades educativas de todos los niños y niñas, asegurar la igualdad de oportunidades en el aprendizaje, y su plena participación e integración. (p.22)

Es decir, la educación inclusiva pretendeeliminarlas barreras que existen para el aprendizaje y la participación de las personas, con el fin de que las diferencias culturales, socioeconómicas, individuales y de género, no se conviertan en desigualdades educativas y, por esa vía, en desigualdades sociales; a la vez, aspira hacer efectivo el derecho a la educación, a la igualdad de oportunidades y a la participación. La población infantil con necesidades educativas especiales, tiene derecho a educarse en un contexto normalizado y plural que asegure su futura integración y participación en una sociedad de por sí diversa. El derecho de toda la población infantil a la educación se encuentra consagrado en la Declaración de los Derechos Humanos y reiterado en las políticas educativas del país.

\section{Supervisión de la educación.}

La supervisión de la educación llega a América como producto de la Revolución Industrial, mediante la influencia de los Estados Unidos, a la vez que como proceso de la influencia de la literatura norteamericana sobre administración de la educación, cuyos pilares son la teoría administrativa empresarial desde fines del siglo XIX y comienzos de XX, con los aportes de Taylor y Fayol en la administración científica y general, mediante la formación de los administradores de acuerdo con un sistema cerrado, jerárquico y con roles bien definidos, con estricta división del trabajo y descripción de los puestos.

Con referencia a lo anterior, tanto el origen de la inspección como la supervisión no se dan en el plano educativo, sino en el sector administrativo. Como indican Castillero et al. (2009), "los temas teóricos, metodológicos y técnicos que se generan en la teoría administrativa norteamericana y se aplican en las organizaciones económico-empresariales, se transfieren a las organizaciones de los diferentes sectores de la sociedad, incluyendo al sector educativo" (p.100). Tanto la inspección como la supervisión son medios de los cuales se vale la administración para que se cumplan las disposiciones legales y tener información de los resultados y comportamientos de los subalternos.

La supervisión tradicionalmente ha estado marcada, según García, Rojas y Campos (2002) "por un estilo autoritario, que es rígido, vertical y elitista. Las premisas básicas que la fundamentan sostienen que el orden debe primar sobre todas las cosas" (p. 283). Este estilo 
de supervisión es el que correspondió al perfil del inspector o inspectora, presente por mucho tiempo en el sistema educativo. Este se consideraba como un agente de control, cuya tarea era el descubrimiento de errores para sancionar.

Al respecto, García et al. (2002) indican que el inspector "es una persona autocrática, reactiva, que fiscaliza y sanciona, que actúa con posteridad para criticar lo ya hecho" (p.283). En la actualidad debemos pensar en un supervisor carismático, proactivo, democrático que se encargue del trabajo con los demás, para mejorar la prestación del servicio educativo, dando prioridad a lo humano, en una posición de apertura comprensión del otro, con habilidad auténtica y sincera en las vivencias de las relaciones humanas.

Hechas la consideraciones anteriores, el término de supervisor como lo plantean Castillero et al. (2009) se puede aplicar en todos los niveles de la administración, a quienes dirigen las actividades de otros; pero se aplica sólo a las personas de los niveles inferiores de la jerarquía administrativa. Los supervisores son administradores cuyas funciones principales consisten en dirigir y coordinar el trabajo de otros, encaminándolos hacia el logro de los objetivos previstos para el grupo, a la vez se concentra en las personas que están bajo su dirección.

Con referencia a lo anterior, el supervisor moderno cumple, como indican Castillero et al. (2009), tanto funciones técnicas como administrativas, las primeras son las que corresponden a la planificación, operación y control de la función de producción y las segundas, implican la dirección del personal, que incluye adiestramiento, asesoría y desarrollo del personal, ambas lo guían hacia el desarrollo de una red de interacciones que le hacen tener una posición clave en la organización.

De acuerdo con los razonamientos que se han venido realizando, se puede indicar que la supervisión viene dando pasos lentos en el mejoramiento de la calidad de la educación, transformando la visión y expectativa de la supervisión que se requiere, la misma debe ser diferente, más intensa y vinculada con el problema de revitalizar le enseñanza y la educación.

En los centros educativos, la persona responsable de la supervisión, es el director o directora, quien realiza diversas funciones, según Castillero et al. (2009), que consisten en:

Velar por la aplicación de la política educativa; ofrecer apoyo técnico pedagógico a los docentes para el desarrollo del proceso de enseñanza -aprendizaje; dotarlos de los recursos necesarios para su trabajo; tener la infraestructura en condiciones satisfactorias para el uso; promover la formación y satisfacción en el trabajo, etc. (p. 102)

De los anteriores planteamientos, se deduce que la supervisión es el medio del cual se vale la dirección para mantener en la ejecución de las tareas, la unidad de las diversidades y la orientación hacia el logro de los objetivos. La supervisión no tiene sentido si no es para 
acompañar y orientar hacia el logro de los objetivos preestablecidos y alcanzar, de esta manera, la mejora educativa que demanda el día de hoy la sociedad postmoderna; para ello, tiene que establecer relaciones estrechas con el docente, de cuya capacidad, habilidad y destreza depende en gran medida el proceso de enseñanza aprendizaje.

Dadas las condiciones que anteceden, Castillero et al. (2009) plantean varias estrategias de acción de las cuales se puede valer la dirección para lograr los objetivos planteados en colaboración con los maestros, las cuales son: directas e indirectas.

a. Directas: dentro de éstas se encuentran las visitas, las reuniones, las entrevistas y las observaciones.

b. Indirectas: encontramos los análisis de documentos, estadísticas, boletines, notas, cuestionarios e informes.

En relación con las visitas como estrategia de acción, Gento (1999) indica que constituyen el procedimiento más generalizado de actuación. Al respecto, menciona que "esta estrategia sirve para comprobar o evidenciar en la propia realidad los datos o hechos objetos de estudio o consideración en un caso" (Gento, 1999, p.203). Las visitas serán distintas si con ellas se trata de llevar a cabo algún tipo de evaluación, o si lo que se pretende a través de ellas es el mejoramiento de algún determinado aspecto, o si de lo que se trata es de impulsar el espíritu y el comportamiento participativo de un determinado grupo de profesionales.

Por otra parte, como indica Gento (1999), se pueden realizar visitas específicas, las cuales "obedecen al tratamiento de temas o aspectos determinados que aparecen en los planes respectivos" (p.206), en ocasiones son incidentales, es decir, que se realizan cuando surgen motivos puntuales o urgentes.

Así mismo, las observaciones, como otra estrategia de acción, son una técnica que consiste en mirar con atención determinado hecho o circunstancia. Como indican Castillero et al. (2009), con ella "nos permitirá verificar el comportamiento de los distintos elementos que componen la institución escolar, antes de que se vea afectada la calidad del proceso de enseñanza aprendizaje por alguna limitación profesional o técnica (...)" (p.114). Si la gestión no cuenta con ningún plan de trabajo, no tendrá nada que organizar, ejecutar o controlar y por supuesto, nada que supervisar. Por tanto, como indican Castillero et al. (2009), "las observaciones deben planearse, para lograr el cumplimiento de una verdadera supervisión" (p. 114).

En referencia a la clasificación anterior, otra de las estrategias de acción contempladas en el grupo de las indirectas, es el análisis de documentos; éstos, como indica Gento (1999), "pueden ser emitidos por los centros escolares y los profesores y que sea remitida a aquella institución, 
ya sea directa e indirectamente (en este caso a través de autoridades administrativas u otros órganos)" (p. 207). El análisis de esta documentación requerirá de un espacio adecuado y una dedicación apropiada.

Por otro lado, como estrategia de acción indirecta está la estadística, la cual indica Lerma (2004) "no es un fin en sí misma, sino una herramienta para analizar los datos" (p. 496). Ésta da los parámetros a mejorar dependiendo de lo que se desea investigar o conocer, apoyando tanto la labor de la dirección como del personal docente, se realiza comparaciones, se obtiene resultados certeros y se buscan soluciones inmediatas. Las estadísticas se pueden presentar a manera de gráficos, histogramas, entre otros.

Otra estrategia indirecta son los cuestionarios, los mismos son utilizados por la persona supervisora para obtener la información sobre alguna situación particular presente en la institución o para conocer la opinión de otros, en relación con el trabajo que realizan sus subordinados. Para Arroyo (2011), el cuestionario es "una lista de preguntas o enunciados escritos que se proponen para obtener información sobre un determinado hecho, situación o para identificar actitudes, opiniones y creencias" (p. 43).

Con referencia a lo anterior, las estrategias tanto directas como indirectas, le permiten a la gestión del centro establecer relaciones personales y continuas. Como plantean Castillero et al. (2009), "facilita que estas relaciones sean positivas y negativas, porque el personal a su vez observa al director y su disposición y comportamiento hacia ellos el logro de los objetivos institucionales" (p. 114).

En ese mismo sentido, a través del proceso de supervisión la dirección condiciona al personal hacia el logro de los objetivos, conociendo problemas y encontrando oportunidades para brindarle la ayuda que contribuirá a obtener soluciones. Como indican Castillero et al. (2009), "es precisamente a través de este proceso como se forman las relaciones positivas o negativas entre el jefe y el subordinado" (p. 113).

En síntesis, la supervisión debe ser algo más que localizar defectos para su corrección, deben investigarse las causas de los problemas y considerarlos en su conjunto; los debe tratar de evitar, lo cual lo realiza mediante su experiencia. La supervisión debe ser constructiva, estudiando a la vez las dificultades y analizarlas dentro de las condiciones existentes (ambiente, objetivos de la educación, naturaleza del alumno, métodos de enseñanza, condiciones físicas de la escuela, recursos económicos y humanos disponibles).

\section{Perfil del docente de educación preescolar.}

La selección de personal es un proceso que debe realizar la gestión del centro, en el caso de designar la docente idónea para la atención de niños y niñas con necesidades educativas 
especiales, lo cual requiere de mucho cuidado, ya que para atender esta población es necesario un perfil que cumpla con ciertas características; por tanto, como indica Arroyo (2011), pertenece al área de gestión de personal que establece el enlace entre las necesidades de la organización en ofrecer un sistema educativo de calidad y las necesidades de satisfacción del personal y profesional de quienes desarrollan los procesos administrativos y curriculares.

En ese mismo sentido, Arroyo (2011), indica que en la selección del personal:

Se trata de seleccionar al mejor candidato o candidata para el puesto vacante, a través de una serie de procedimientos eficaces entre los que se incluyen, pruebas de habilidad (cognitivas, físicas y motoras), de personalidad y rendimiento; también las muestras y simulaciones del trabajo, así como entrevistas. El Servicio Civil Docente se encarga de ello, pero en las situaciones planteadas, el director tiene injerencia en la selección del personal. Es importante recalcar que a nivel interno el director, consciente o inconscientemente, realiza una selección del personal cuando ubica con criterio técnico y, con base en las necesidades institucionales, a su personal, en los diferentes grados, secciones y niveles educativos. (pp. 35-36).

En relación con lo anterior, Stainback y Stainback citados por Ávila y Esquivel (2009), plantean que al igual que existen decisiones y recomendaciones para promover la inclusión en los grupos regulares, existe un aspecto importante que debe ser tomado en cuenta a la hora de seleccionar el personal, el cual es el compromiso de los docentes, quienes deben recibir la información y preparación sobre educación inclusiva y sobre inclusión, en general. De no ser así, se corre el riesgo de que éste, no valore a todos los alumnos y alumnas como miembros valiosos e iguales, independientemente de sus características particulares.

Es por ello que, en las organizaciones educativas la dirección es la encargada de seleccionar dentro de su personal con criterio técnico, el docente idóneo para trabajar y desarrollar verdaderos procesos de inclusión dentro del grupo, con la población infantil con necesidades educativas especiales.

En este orden de ideas, cabe manifestar que se le debe ofrecer al docente, mediante diversos espacios, los recursos que le permitan sensibilizarse, capacitarse y comprometerse con la inclusión de la población infantil con alguna necesidad o característica peculiar en los grupos regulares.

Sobre la base de las consideraciones anteriores, Ávila y Esquivel (2009) proponen que dentro de la organización se debe seleccionar una persona que actúe como coordinadora de apoyo, cuya misión es "trabajar en colaboración con otras personas del centro escolar para garantizar que sean satisfechas todas las necesidades de los estudiantes en el aula" ( $p$. 76). Entendiendo el trabajo colaborativo como la posibilidad del trabajo conjunto, donde 
todos contribuyen a promover sistemas de apoyo y adaptar la enseñanza a las necesidades individuales. Nadie asumirá funciones de experto, supervisor o evaluador.

En la educación preescolar, las docentes asumen el papel de mediadoras, por lo tanto, debe asumir un papel dinámico, reflexivo y analítico en la práctica pedagógica, tomando en cuenta las características, necesidades, experiencias e intereses de los educandos, la cotidianidad del grupo y el entorno.

Cabe agregar, que el perfil del docente de educación preescolar, desde la gestión del centro, está conformado por una serie de criterios de selección de personal, los cuales corresponden a las cualidades personales, sociales e intelectuales, las cuales se detallan a continuación.

Las cualidades personales, como indica Jiménez (1990) citado por el Ministerio de Educación Pública (MEP, 1999), "son los rasgos de personalidad que se determinaron como necesarios en el desempeño del puesto por la calidad de relación interpersonal que se requiere y las situaciones laborales que se presentan" (p.140). Es por ello, que la docente de educación preescolar ha de contar con una serie de cualidades personales para lograr que su labor sea un vehículo de aprendizaje para la población infantil, reconociéndole su aptitud didáctica y pedagógica. Para ello, debe contar con las siguientes cualidades personales, retomando lo expuesto por Jiménez (1990):

- Mantener el dominio de sí misma.

- Pacientes y tolerantes en el trato de los niños.

- Optimista ante situaciones adversas.

- Facilitar un ambiente confortable entre quienes le rodean.

- Dominar las actividades propias de su trabajo.

- Innovar en las actividades que realiza

- Resolver situaciones imprevistas.

- Capaz de organizar su trabajo, de manera quincenal, semanal o diario.

- Respetar los valores culturales del grupo.

- Mostrar interés de superación personal y profesional. (p.15)

Además de las cualidades personales, la docente de educación preescolar, debe contar con diversas cualidades sociales las cuales le permitirán interactuar con los educandos, docentes, padres de familia o encargado, y comunidad, de manera activa y participativa, para el logro del bien individual y común. Como indica Jiménez (1990):

Las cualidades sociales son aquellos rasgos que mantienen cierta permanencia en 
el comportamiento total de la persona y que constituyen la diferenciación individual que es importante conocer, considerar y orientar en el maestro Preescolar. Deben referirse a su capacidad de dirigir su conducta y de adoptar una posición personal frente a distintas situaciones, y sus propias características, capacidades e intereses. (p.17)

Dentro de las cualidades sociales propuestas por Jiménez (1990), se encuentran:

- Desarrollar relaciones interpersonales con niños y padres de familia o encargado.

- Mostrar actitudes positivas entre los compañeros de trabajo.

- Buena comunicación entre el personal docente. ( p.15)

Es por ello, que la docente de preescolar debe fortalecer las cualidades sociales, con la finalidad de lograr una comunicación paralela y asertiva con la comunidad estudiantil, padres de familia y compañeros de trabajo.

Por último, se presentan las cualidades intelectuales, como indica Jiménez (1990), "son el conjunto de conocimientos teórico prácticos necesarios para la labor en Preescolar" (p.18). Dentro de las cualidades intelectuales propuestas por el autor, se encuentran:

- Capaz de aplicar los conocimientos a situaciones que se le presentan.

- Capacidad de comprensión verbal, para lograr una comunicación paralela.

- Tener capacidad de análisis y síntesis.

- Tener capacidad de percepción de las necesidades y problemas de los niños. (p.15)

Cabe agregar que para enriquecer las cualidades intelectuales que ha de poseer el docente de educación preescolar a la hora de trabajar con la población infantil con necesidades educativas especiales, se toman en cuenta las siguientes cualidades intelectuales mencionadas por Grau citado por Echeverría (2011) de las docentes de educación especial, importantes de fomentar en los docentes de educación preescolar. A saber:

- Asistencia a talleres, capacitaciones y cursos.

- Selección y utilización de métodos de enseñanza individual y variada.

- Conocimiento y aplicación de técnicas de modificación de conducta individual y grupal.

- Aplicación de estrategias de motivación para mejorar el clima psicológico del aula. (p.67)

Con referencia a lo anterior, se extrae que la docente que ha de trabajar un verdadero proceso de inclusión con la población infantil con necesidades educativas especiales, debe contar con una serie de cualidades, que ayudarán en el trabajo y desenvolvimiento, tanto 
institucional como grupal, para el logro de una educación inclusiva de calidad, donde los más beneficiosos sean los educandos, padres de familia o encargado y el centro educativo en general.

\section{Estrategias de intervención desarrolladas por la gestión, en el proceso de inclusión.}

La gestión de los centros educativos requiere desarrollar estrategias de intervención apoyados en procesos de planificación que les permitan diseñar y realizar diferentes proyectos, desde su gestión, creando espacios de trabajo, para dar respuesta atinada y oportuna a las demandas inherentes a la educación, sin perder de vista que la educación es responsabilidad de todos. Como indican Garbanzo y Orozco (2007), "no es un problema exclusivo del Ministerio de Educación Pública, ni de los políticos, sino de todos los involucrados en distintos niveles de responsabilidad del sistema educativo" (p.106).

En ese mismo sentido, la inclusión implica que la población infantil de una determinada comunidad aprenda juntos, independientemente de sus condiciones personales, sociales 0 culturales. Como indica el CENAREC (2004):

Se trata de lograr una escuela en la que no existan "requisitos de entrada" ni mecanismos de selección o discriminación de ningún tipo; una escuela que modifique substancialmente su estructura, funcionamiento y propuesta pedagógica para dar respuesta a las necesidades educativas de todos y cada uno de los niños y niñas, incluidos aquellos que presentan una discapacidad. Desde esta perspectiva, es la escuela la que debe adaptarse a los niños y no éstos a la escuela (pp. 22-23).

La supervisión toma en cuenta técnicas tanto directas como indirectas, las cuales permiten establecer relaciones personales y continuas. Este proceso facilita que las relaciones que se establezcan sean tanto positivas como negativas, porque a la vez, el personal observa al director o directora, su disposición y comportamiento hacia ellos y el logro de los objetivos institucionales.

Al respecto, resulta oportuno, definir lo que es estrategia. Para Arroyo (2011), una estrategia es:

Como el plan que establece, ordena y asigna la secuencia lógica de un conjunto de acciones por ejecutar a largo plazo, en la organización educativa. Esta debe ser diseñada de manera consciente, atendiendo tanto las debilidades como las amenazas, así como aprovechando las fortalezas y oportunidades para situar a la organización educativa en una posición concreta predefinida en la visión. (p. 47)

Realizadas las consideraciones anteriores, se presentan las siguientes estrategias propuestas por Castillero et al. (2009), que sirven de guía a la dirección en el proceso de supervisión de la inclusión de la población infantil con necesidades educativas, en los grupos regulares. 
Programas de visitas: consiste en la elaboración de un enlistado de los departamentos o servicios a los cuales debe dirigirse el personal de supervisión, de acuerdo con la frecuencia que se haya estimado necesarias y las fechas en que deben realizarse las visitas.

Se pueden implementar dos tipos de programas de visitas:

a. Programa anual de visitas: en la realización de un verdadero programa de visita, como indican Castillero et al. (2009), "se discutirá la cantidad y la calidad del trabajo a desarrollar en cada visita y el orden de prioridad de cada una de ellas, teniendo presente como se ha dicho, el proyecto educativo de centro y el proyecto curricular" (p.115)

b. Programa mensual de visitas: en un programa mensual de visitas lo que se supervise depende de lo que el director o directora desee para su organización, tomando en cuenta tanto lo administrativo como lo curricular. Según Castillero et al. (2009):

Cada coordinador del ámbito de gestión, elaborará su programa a corto plazo, y días antes de empezar el mes que este programa cubre, debe recoger en él la realidad de las situaciones, o, simplemente acercará más a éstas, tomando en cuenta las variaciones, así como las que se preveían para el momento (p.115).

Programas de actividades por visita: como indican Castillero et al. (2009), el programa de actividades por visitas "son listas de las diferentes actividades básicas que debe desarrollar el que va a supervisar al llegar al lugar indicado en un programa de visitas" (p.115). Con ello, se pretende detectar las posibles dificultades. El supervisor o supervisora debe estar instruido en lo que debe buscar al analizar cada uno de los puntos de lo observado y, en caso de identificar alguna anomalía, debe investigar el porqué de ella, luego explicará y demostrará como corregirla. En algunos casos se darán las recomendaciones verbales o por escrito, pero en otras se recomendarán cursos, charlas o seminarios.

Esta supervisión se debe programar en conjunto con el personal para que se conozca y no sorprenda a nadie cuando es supervisado. Es importante destacar, como mencionan Castillero et al. (2009), que la supervisión "no tiene sentido si no es para orientar, acompañar al personal hacia un mejor desempeño y el logro de los objetivos. De no ser así como menciona se convierte fácilmente en medio de persecución y fiscalización" (p.116).

Programa de desarrollo profesional: como mencionan Castillero et al. (2009), el programa de desarrollo profesional,"son todas aquellas actividades sistemáticas, cursos cortos, seminarios, ciclos de conferencias, etc." (p.116). 
Las mismas son promovidas y organizadas por el gestor o gestora con el propósito de mejorar la calidad de los servicios que prestan los docentes que tiene a su cargo. Tomando como base el análisis de las observaciones e información obtenidas en las visitas, la dirección estará en la posibilidad de organizar o proponer, a las instancias respectivas, actividades con miras al mejoramiento de la actitud y conocimientos técnicos del personal de la institución. Según Castillero et al. (2009) "es recomendable que al planificar el programa de desarrollo profesional colabore con el director el personal que lo va a recibir" (p.117).

El éxito de la inclusión está en la capacidad del gestor o gestora del centro de motivar al personal docente y hacer conciencia de los cambios que se deben implementar para trabajar con la población infantil con necesidades educativas especiales y favorecer de manera significativa el proceso de enseñanza y aprendizaje.

Por las consideraciones anteriores, el tema adquiere relevancia en la gestión del centro educativo, en tanto el profesional en gestión esté consciente de la labor como guía y orientador del docente en el proceso de inclusión de la población infantil con necesidades educativas especiales, con la finalidad de lograr aprendizajes significativos, de acuerdo con las características y necesidades particulares.

En efecto, todo ello se realizará con el aporte del cuerpo docente y administrativo en bienestar de la población educativa, haciendo valer su derecho a la educación, al amparo de las normas y lineamientos que en materia de inclusión ha venido insertando el MEP en las organizaciones educativas de Costa Rica.

\section{Referente metodológico}

La investigación realizada se enmarca dentro del enfoque cuantitativo descriptivo, por su carácter y profundidad, ya que busca analizar la gestión del centro en el proceso de inclusión de la población infantil con necesidades educativas especiales, en los grupos regulares de educación preescolar. El propósito de los estudios descriptivos, según Hernández, Fernández y Baptista (2003), se definen como aquellos que buscan:

Describir situaciones, eventos y hechos. Esto es decir cómo es y cómo se manifiesta determinado fenómeno. Los estudios descriptivos buscan especificar las propiedades, las características y los perfiles importantes de personas, grupos, comunidades o cualquier otro fenómeno que se someta a un análisis. (p. 117)

En el orden de las ideas anteriores, se define el trabajo de investigación como descriptivo porque pretende recopilar la información necesaria sobre la inclusión de la población infantil con 
necesidades educativas especiales en los grupos regulares y el proceso que realiza la gestión en cuatro jardines de niños independientes de la provincia de Cartago, circuitos escolares 04, 05, y 06, de la Dirección Regional de Educación de Cartago. Para ello, se contó con la participación de dieciséis docentes del Ciclo Materno Infantil y veintitrés del Ciclo de Transición, además de dos docentes de inglés, para un total de cuarenta y un docentes, así como las cuatro directoras de las instituciones participantes en el estudio.

Para el trabajo de investigación, se utilizaron como fuentes de información primarias las directoras y docentes del Ciclo Materno Infantil y Ciclo de Transición de los Jardines de Niños independientes Ascensión Esquivel, Jesús Jiménez, República Francesa y Ricardo Jiménez Oreamuno, pertenecientes a la Dirección Regional de Educación de Cartago, circuitos escolares 04, 05 y 06. Las fuentes secundarias se conforman de documentos escritos: libros, revistas, artículos tanto nacionales como internacionales, en forma física y digital, así como trabajos finales de graduación, también en el nivel internacional y nacional.

En relación con la recolección de la información, se elaboró un cuestionario que se validó tomando una pequeña muestra de sujetos similares a los que se emplearon en el trabajo real, conformada por docentes del Ciclo Materno Infantil y Ciclo de Transición y la directora del Jardín de Niños Independiente El Conejito Feliz, ubicado en la provincia de Cartago, Cantón Oreamuno, Distrito San Rafael, circuito escolar 07.

El instrumento fue organizado en tres partes:

- I PARTE: se pretende determinar las estrategias de supervisión que realiza la gestión del centro, en relación al proceso de inclusión de la población infantil con necesidades educativas especiales, en los grupos regulares de educación preescolar.

- II PARTE: se busca identificar los criterios de selección de personal que utiliza la gestión del centro para asignar los docentes, para atender a la población infantil con necesidades educativas especiales, en los grupos regulares de educación preescolar.

- III PARTE: se indaga sobre el proceso realizado por la gestión del centro, al implementar las estrategias de intervención en el proceso de inclusión de la población infantil con necesidades educativas especiales, en los grupos regulares de educación preescolar.

\section{Sistematización y análisis de la información}

El análisis gira alrededor de tres aspectos: determinar las estrategias de supervisión que realiza la gestión del centro; identificar los criterios de selección de personal que utiliza la gestión del centro y describir el proceso realizado por la gestión del centro al implementar las 
estrategias de intervención en el proceso de inclusión de la población infantil con necesidades educativas especiales, en los grupos regulares de educación preescolar.

\section{Análisis de las estrategias de supervisión en el proceso de inclusión de la población infantil con necesidades educativas especiales.}

La tipificación de las estrategias de supervisión empleadas por la gestión, es relevante para el estudio debido a que se considera que, identificando las estrategias se determina si la gestión lleva a cabo un verdadero proceso de supervisión, en cuanto al proceso de inclusión en los grupos regulares de educación preescolar de la población infantil con necesidades educativas especiales.

En la siguiente figura se presentan las estrategias de supervisión utilizables en la gestión del centro.

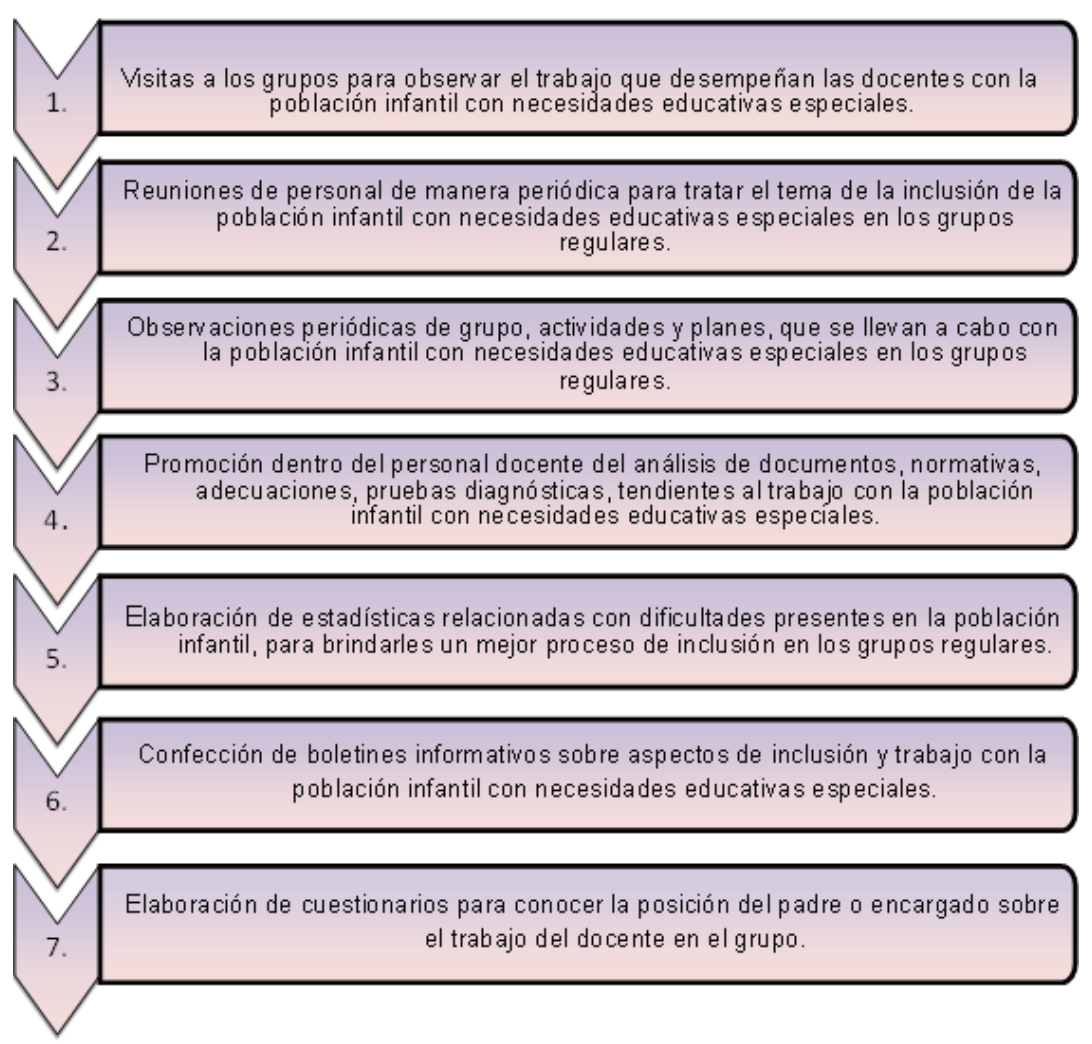

Figura 1: Estrategias de supervisión que utiliza la gestión del centro, en el proceso de inclusión de la población infantil con necesidades educativas especiales en los grupos regulares de educación preescolar

Fuente: Gómez, 2012. 
La gestión de las cuatro instituciones participantes en el estudio debe reforzar las estrategias de supervisión expuestas en la figura 1, con la finalidad de brindarle a la población infantil con necesidades educativas especiales, una educación de calidad, acorde con sus capacidades y necesidades. Deben además, tener presente y analizar las políticas que se han girado en el nivel internacional y nacional, en relación a la educación inclusiva. Recordar que esta surge del reconocimiento como un derecho humano básico, de todos y no de unos pocos, y como un principio indispensable para el desarrollo individual y social que promueve la paz, la libertad y la justica, en contraposición con la exclusión, la discriminación, a la ignorancia y a la guerra.

Gráfico 1. Estrategias de supervisión utilizadas por la gestión del Jardín de Niños República Francesa, en el proceso de inclusión de la población infantil con necesidades educativas especiales en los grupos regulares de educación preescolar, 2012 (Cifras relativas)

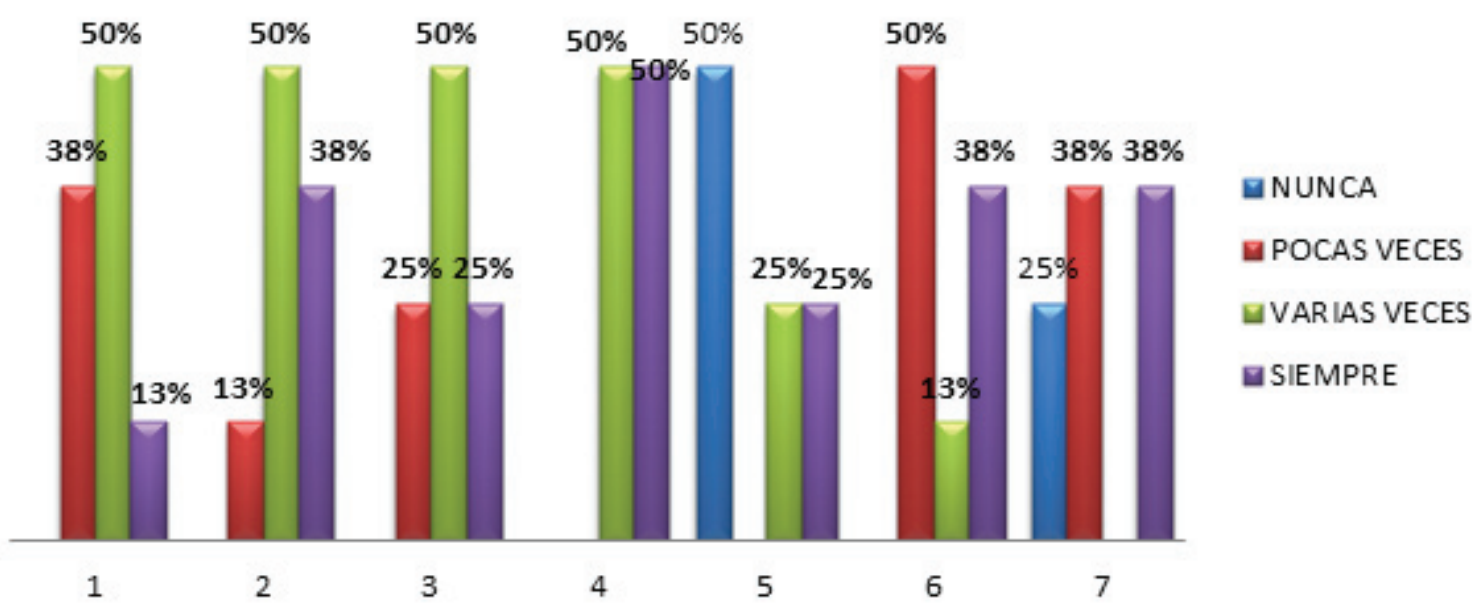

Fuente: Cuestionario aplicado a las docentes del Jardín de Niños República Francesa, 2012.

Los números que aparecen al pie del gráfico corresponden a las siete estrategias de supervisión expuestas en la figura 1. Por lo anterior, en el gráfico 1 se evidencia que ninguna de las estrategias de supervisión alcanza el mínimo establecido por el investigador, el cual es el 70\%, por tanto, no están presentes en la organización y deben integrarse como parte de la gestión del centro, en relación con el proceso de inclusión de la población infantil con necesidades educativas especiales en los grupos regulares de la educación preescolar. 


\section{Análisis de los criterios de selección de personal que debe poseer el docente que trabaja con la población infantil con necesidades educativas especiales.}

Dentro de los criterios de selección de personal que utiliza la gestión para la incorporación de la población infantil con necesidades educativas especiales a los grupos de preescolar, se encuentran las cualidades personales, cualidades sociales y cualidades intelectuales. Al respecto, la figura 2 refiere las cualidades que debe poseer el docente para una debida atención de la población infantil con necesidades educativas especiales.

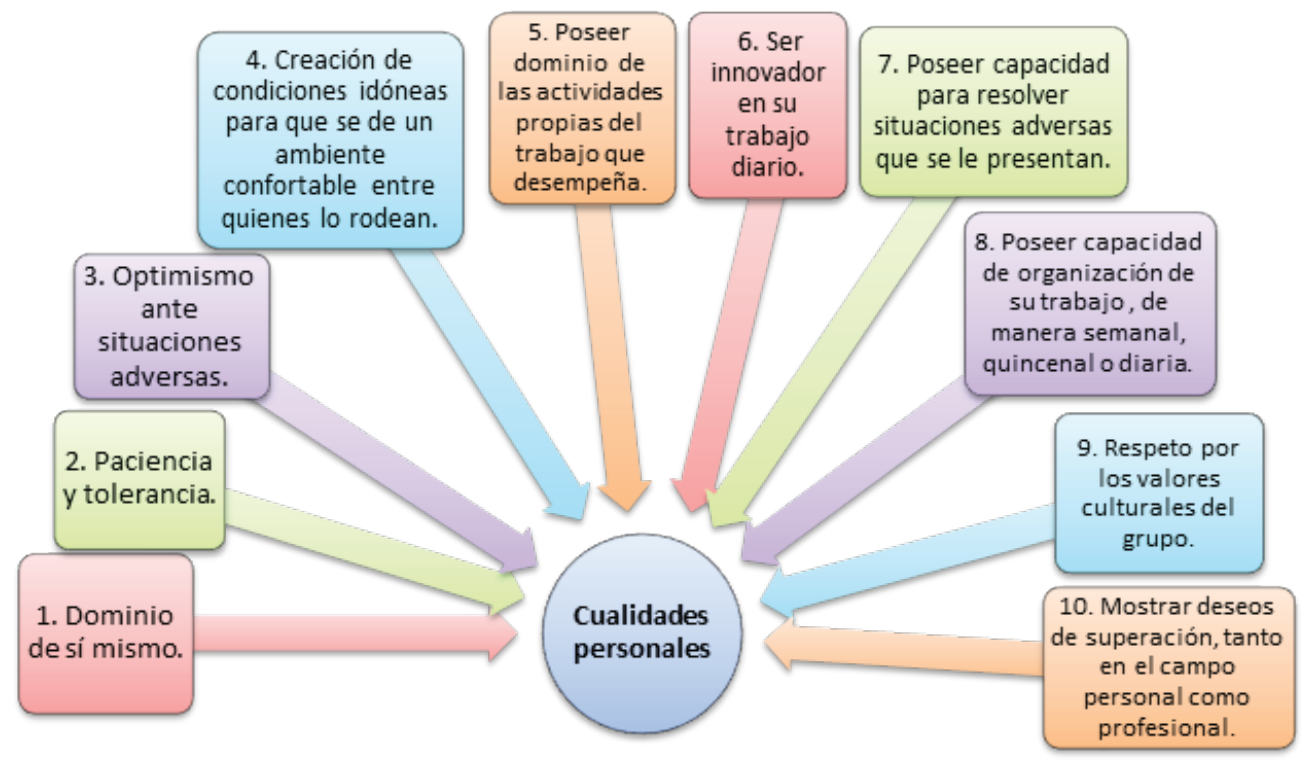

Figura 2. Cualidades personales que debe poseer el docente que trabaja con la población infantil con necesidades educativas especiales

Fuente: Gómez, 2012.

Tomando como base los resultados brindados por las docentes participantes en la investigación, relacionados con las cualidades personales utilizadas por la gestión de los cuatro jardines de niños participantes para la asignación en los grupos de la población infantil con necesidades educativas especiales, se tiene que uno de ellos ha de reforzar nueve de las cualidades personales y otro, las diez cualidades personales; otros dos no tienen que reforzar ninguna de las diez cualidades personales, ya que sobrepasan el mínimo establecido, tal como se muestra en el siguiente gráfico. 
Gráfico 2. Cualidades personales utilizadas por la gestión del Jardín de Niños Ascensión Esquivel, en la selección del personal, para la asignación en los grupos de la población infantil con necesidades educativas especiales, 2012 (Cifras relativas)

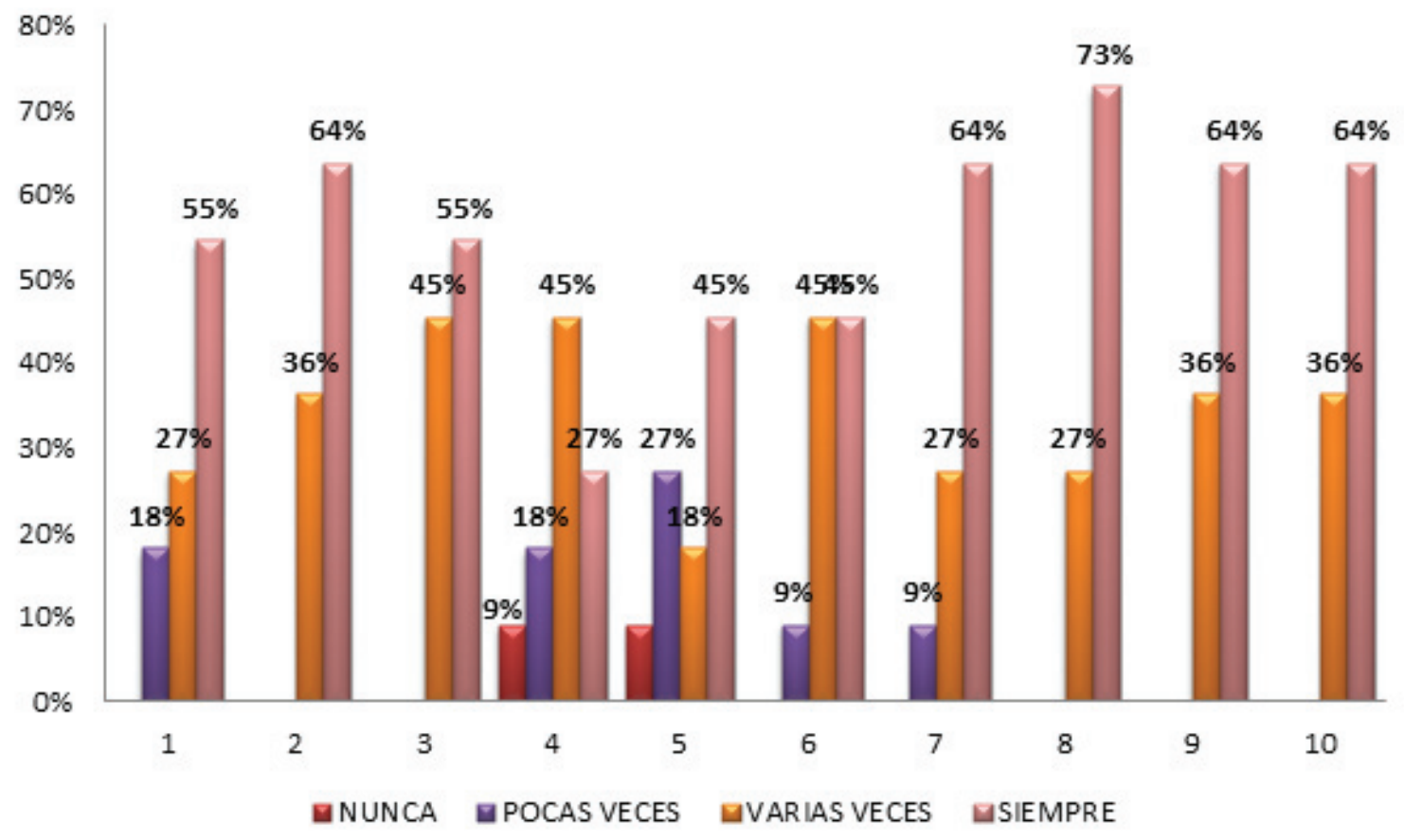

Fuente: Cuestionario aplicado a las docentes del Jardín de Niños Ascensión Esquivel, 2012.

Cabe destacar que los números que aparecen al pie del gráfico, corresponden a las diez cualidades personales que debe poseer el docente que trabaja con la población infantil con necesidades educativas especiales, presentados en la figura 2.

Para la gestión de los centros infantiles, es importante considerar las cualidades personales para ofrecerle a la población infantil con necesidades educativas especiales la oportunidad de avanzar en el sistema educativo, según sus posibilidades. En el gráfico queda de manifiesto aquellas cualidades que debe enriquece el personal docente para la debida atención de la población infantil en los procesos regulares de la educación preescolar.

En relación con las cualidades sociales, la figura 3 presenta aquellas que son de relevancia para el docente en preescolar, con el fin de atender a los niños y niñas con necesidades educativas especiales. 


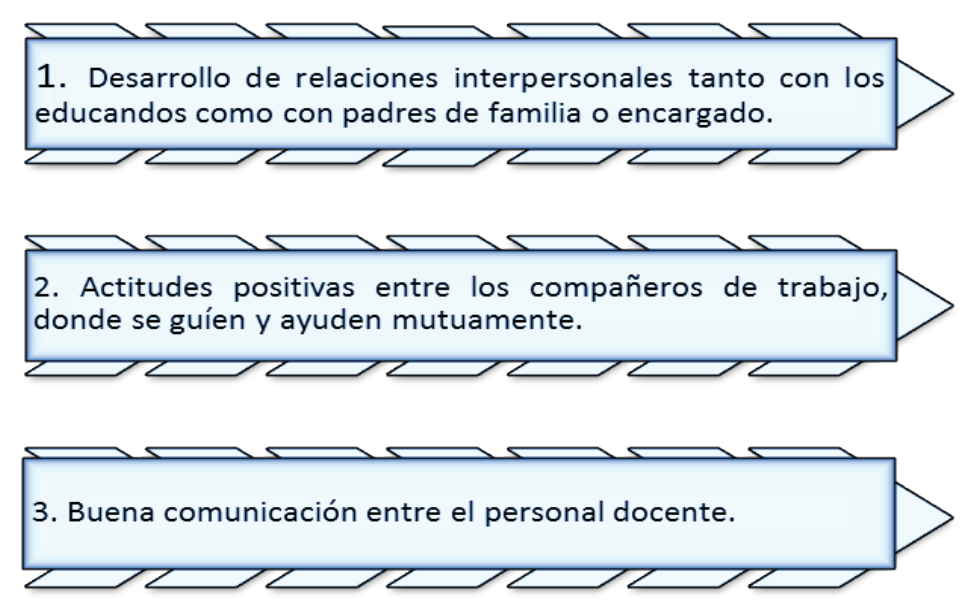

Figura 3. Cualidades sociales que debe poseer el docente que trabaja con población infantil con necesidades educativas especiales

Fuente: Gómez, 2012.

Observando los resultados extraídos de la información brindada por las docentes de las cuatro instituciones participantes en el estudio, en relación con las cualidades sociales, se tiene que el Jardín de Niños Ascensión Esquivel debe reforzar las cualidades sociales uno y tres, el Jardín de Niños Ricardo Jiménez Oreamuno, las cualidades sociales dos y tres, y el Jardín de Niños República Francesa, únicamente la cualidad social dos. Solamente una institución de las cuatro, no tienen que reforzar ninguna de las diez cualidades personales, ya que sobrepasan el 70\% del mínimo establecido por la investigadora, tal como se muestra en el gráfico 3. 
Gráfico 3. Cualidades sociales utilizadas por la gestión del Jardín deNiños Ricardo Jiménez Oreamuno, en la selección de personal, para la asignación en los grupos de la población infantil con necesidades educativas especiales, 2012 (Cifrasrelativas)

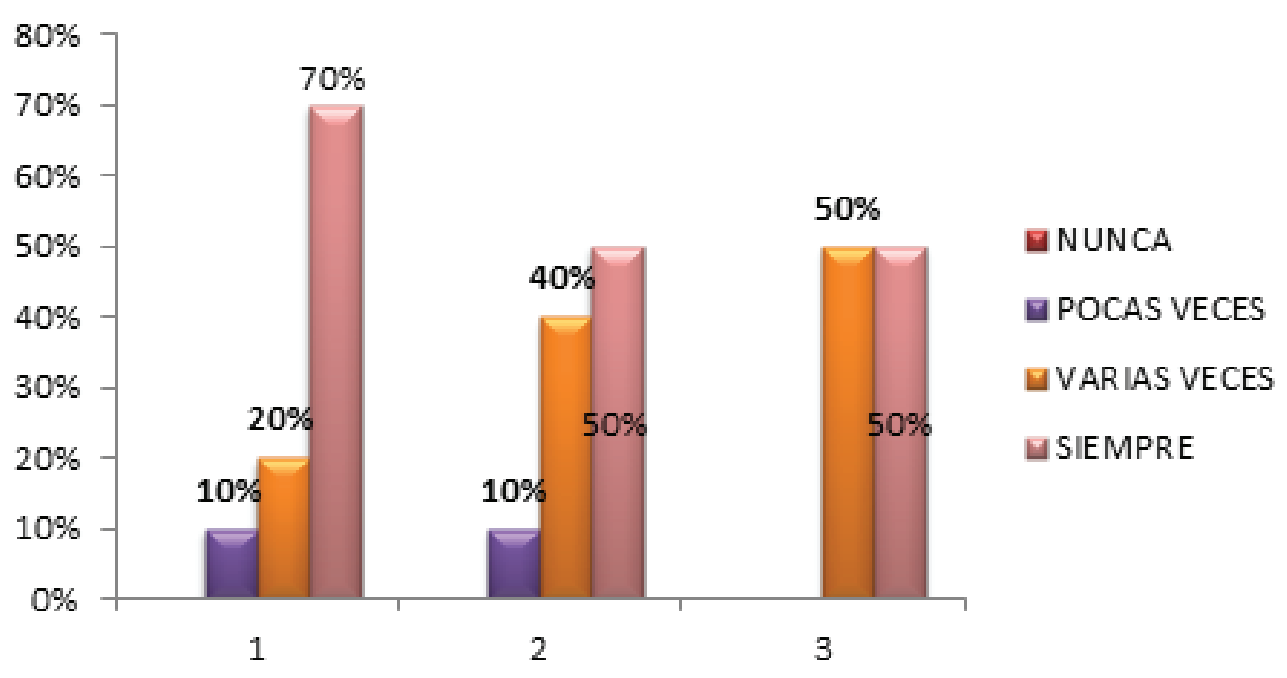

Fuente:Cuestionario aplicado a las docentes del Jardín de Ricardo Jiménez Oreamuno, 2012.

Los números que aparecen al pie del gráfico, conciernen a las tres cualidades sociales que debe poseer el docente que trabaja con la población infantil con necesidades educativas especiales, las mismas se presentaron en la figura 3.

En sí, las cualidades sociales son necesarias en la gestión que realiza cada directora en los centros infantiles, para fortalecer las relaciones interpersonales entre los educandos y padres de familia o encargado, así como para crear un ambiente de colaboración y ayuda mutua entre los compañeros de trabajo, donde prevalezca la comunicación y participación de todos los involucrados en el proceso de inclusión de la población infantil con necesidades educativas especiales en los grupos regulares, con el propósito de brindarles una educación de calidad acorde con sus necesidades. 


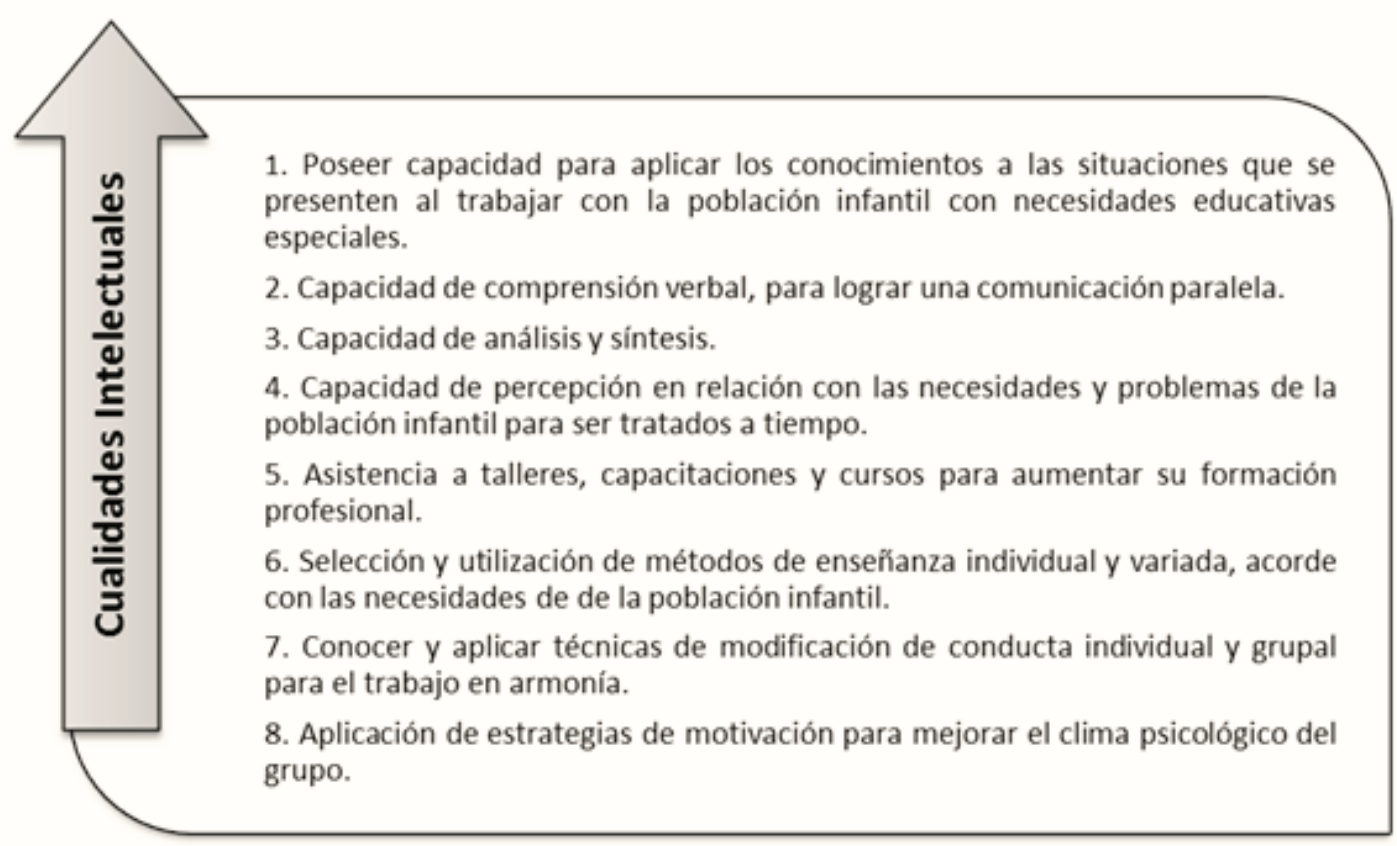

Figura 4. Cualidades intelectuales que debe poseer el docente que trabaja con la población infantil con necesidades educativas especiales

Fuente: Gómez, 2012.

Se pone de manifiesto, tomando como referencia la información suministrada tanto por la directora como las docentes participantes en el estudio que, a excepción del Jardín de Niños Jesús Jiménez, la gestión de los Jardines de Niños Ascensión Esquivel, República Francesa y Ricardo Jiménez Oreamuno deben reforzar de una a dos cualidades intelectuales, con el objetivo de que se de en la organización y por ende, en los grupos de preescolar, un ambiente donde se desarrollen las relaciones interpersonales que son de suma importancia para fortalecer los lazos y la comunicación entre el educador - educando - padres de familia o encargado, así como la promoción de una buena comunicación. Lo anterior, se muestra en el siguiente gráfico. 
Gráfico 4. Cualidades intelectuales utilizadas por la gestión del Jardín de NiñosRepública Francesa, en la selección del personal, para laasignación en los grupos de la población infantilcon necesidades educativas especiales, 2012 (Cifras relativas)

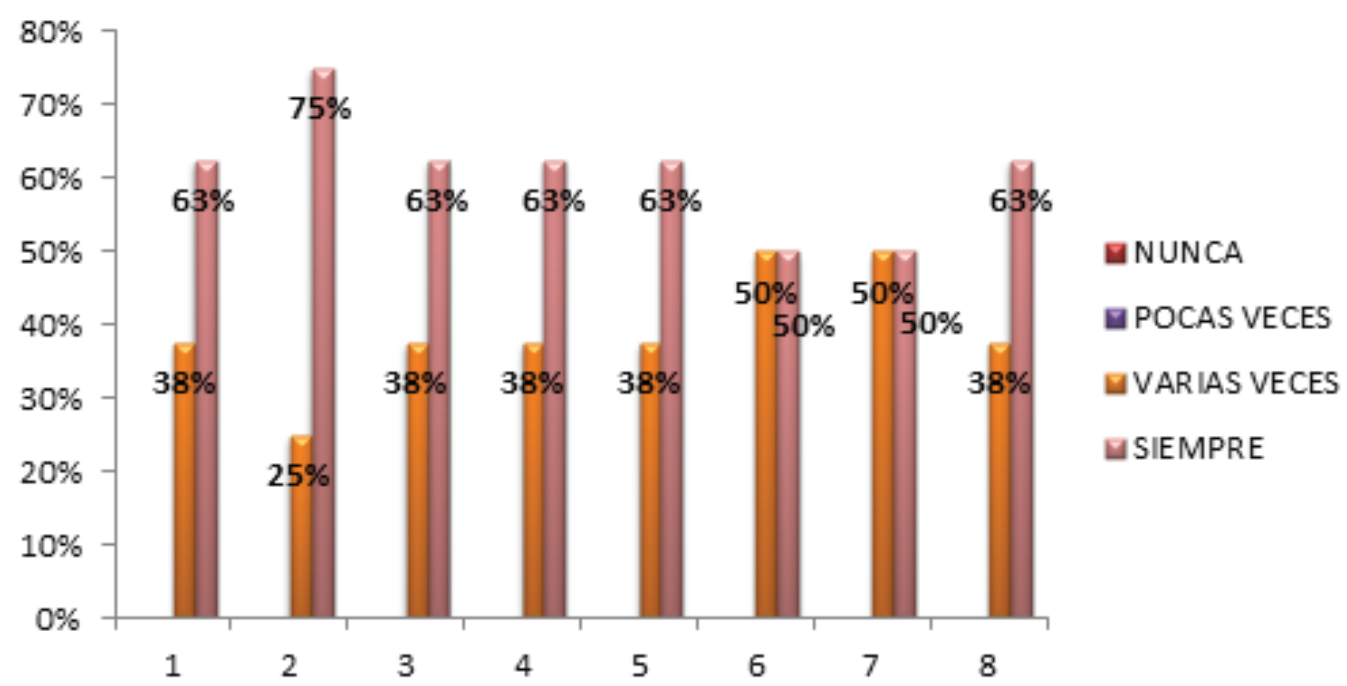

Fuente: Cuestionario aplicado a las docentes del Jardín de Niños República Francesa, 2012.

Los números que aparecen al pie del gráfico, atañen a las ocho cualidades intelectuales que debe poseer la docente que trabaja con la población infantil con necesidades educativas especiales, las mismas se presentaron en la figura 4.

Se ha de destacar la importancia de las cualidades intelectuales para la gestión de los centros infantiles, con la finalidad de concientizar al cuerpo docente en la creación de ambientes más propicios para el desenvolimiento y aprendizaje de la población infantil con necesidades educativas especiales, al ser integrados en los grupos regulares. Como indica Jiménez (1990), las cualidades intelectuales "son el conjunto de conocimientos teórico prácticos necesarios para la labor en Preescolar" (p.18). Mismos que debe poseer todo docente de educación preescolar para brindar una educación inclusiva de calidad.

Estrategias de intervención en el proceso de inclusión de la población infantil con necesidades educativas especiales, en los grupos regulares de educación preescolar.

Los gestores y gestoras de la educación requieren desarrollar estrategias de intervención apoyados en procesos de planificación que les permita diseñar y realizar diferentes proyectos 
desde su gestión, creando espacios de trabajo para dar respuesta atinada y oportuna a las demandas inherentes a la educación, sin perder de vista que la educación es responsabilidad de todos.

En la siguiente figura, se presentan las estrategias propuestas por Castillero et al. (2009), que sirven de guía a la dirección en el proceso de supervisión de la inclusión de niños con necesidades educativas a los grupos regulares de educación preescolar

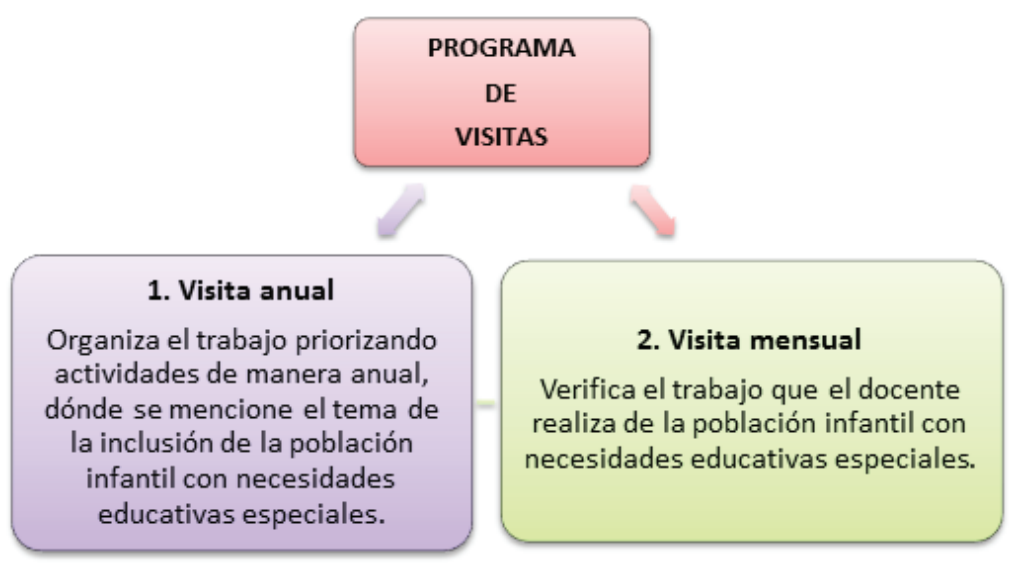

Figura 5 . Estrategias de intervención desarrolladas por la gestión en el proceso de inclusión de la población infantil con necesidades educativas especiales, en los grupos regulares de preescolar

Fuente: Gómez, 2012.

La información brindada por las docentes participantes en el estudio, indican que tanto en el Jardín de Niños Jesús Jiménez como en el Ricardo Jiménez Oreamuno, la gestora educativa si realiza tanto las visitas anuales como las mensuales; no así la directora de los Jardines de Niños Ascensión Esquivel y República Francesa. Los datos suministrados se presentan en el siguiente gráfico. 
Gráfico 5. Estrategias de intervención desarrolladas por la gestión del Jardín de Niños República Francesa, en el proceso de inclusión de la población infantil con necesidades educativas especiales, 2012 (Cifrasrelativas)

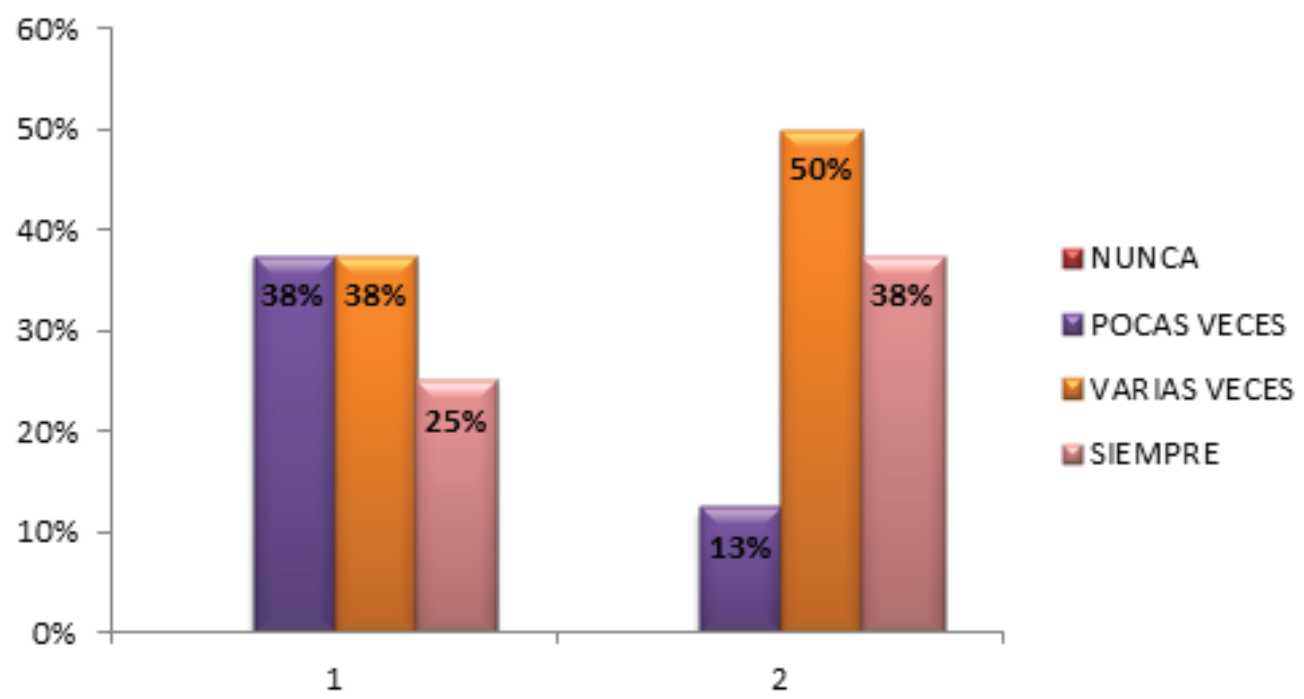

Fuente: Cuestionario aplicado a las docentes del Jardín de Niños República Francesa, 2012.

Los números que aparecen al pie del gráfico corresponden a las dos estrategias de intervención desarrolladas por la gestión del centro en el proceso de inclusión de la población infantil con necesidades educativas especiales, en los grupos regulares, presentadas en la figura 5.

Resulta oportuno reiterar que tanto las visitas anuales como las mensuales, abren espacios para que las docentes evacuen dudas, compartan ideas y externen la situación que ellas viven en los grupos regulares, cuando dentro de sus clases cuentan con población infantil con alguna dificultad de aprendizaje. Es función de la dirección, en su rol supervisor, orientar el trabajo que están desarrollando y llevan a cabo los docentes en relación a la inclusión, con el fin de brindarles una educación de calidad, acorde con sus capacidades y necesidades.

Otro apartado que se contempla en las estrategias de intervención en el proceso de inclusión de la población infantil con necesidades educativas especiales, es el programa de actividades por visitas. Las mismas pretenden descubrir los puntos débiles a observar para detectar las posibles dificultades que se están presentando en la organización.

Según Castillero et al. (2009), "el programa de actividades por visita: son listas de las 
diferentes actividades que debe desarrollar el que va a supervisar al llegar al lugar indicado en un programa de visitas" (p.115). En la siguiente figura se presentan las actividades por visita.

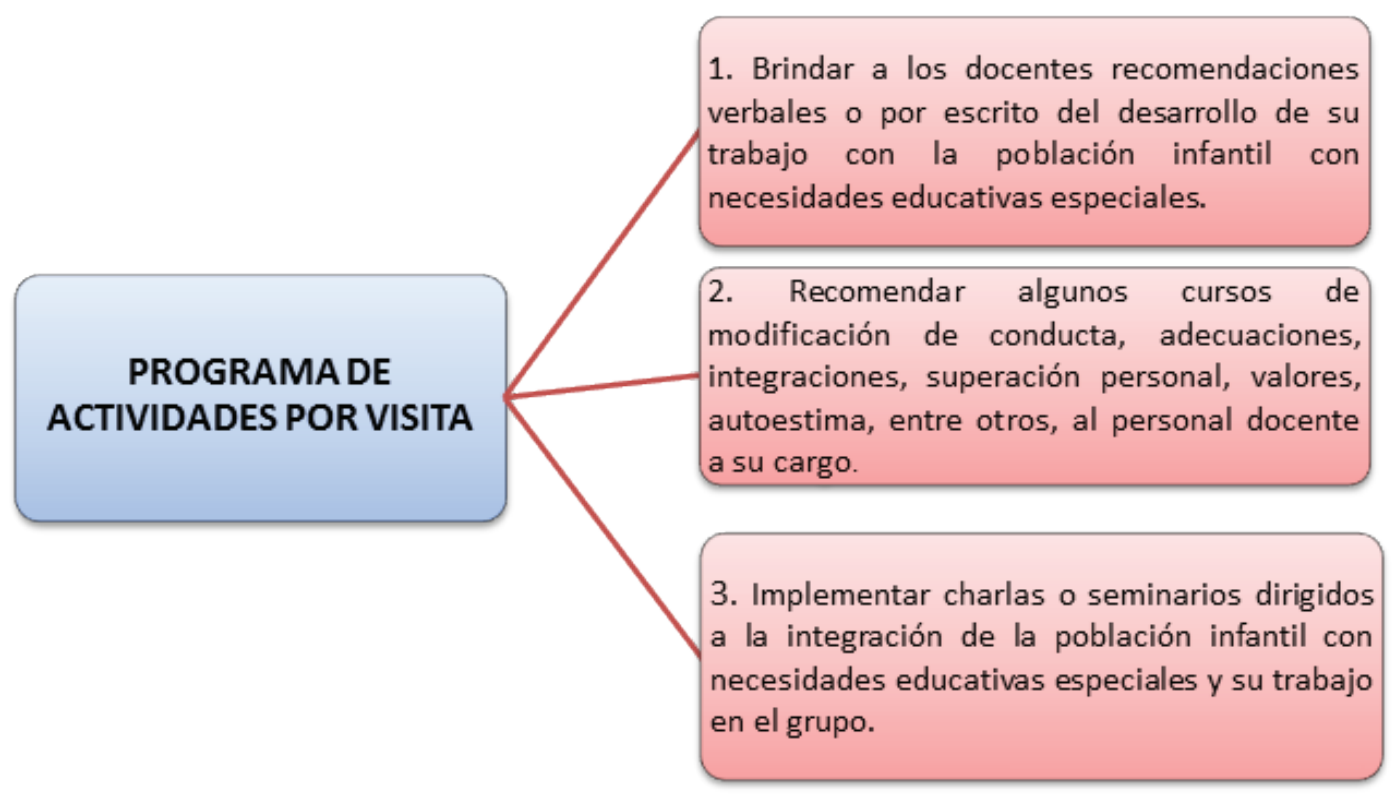

Figura 6. Programa de actividades por visita que realiza la gestión del centro

Fuente: Gómez, 2012.

En referencia a los resultados mencionados, concernientes con el programa de actividades porvisitas desarrollado por la gestión del centro en el proceso de inclusión de la población infantil con necesidades educativas especiales, se tiene que, de las cuatro instituciones participantes en el estudio, únicamente en el Jardín de Niños Jesús Jiménez están presentes las tres actividades, lo que evidencia que la gestora del centro motiva al personal docente y las estimula a participar de cursos, charlas y seminarios, con la finalidad de implementar los cambios necesarios para trabajar con la población infantil con necesidades educativas especiales y favorecer de manera significativa el proceso de enseñanza y aprendizaje. 
Gráfico 6. Programa de actividades por visita desarrollado por la gestión del Jardín de Niños Ascensión Esquivel, en el proceso de inclusión de la población infantil con necesidades educativas especiales, 2012 (Cifrasrelativas)

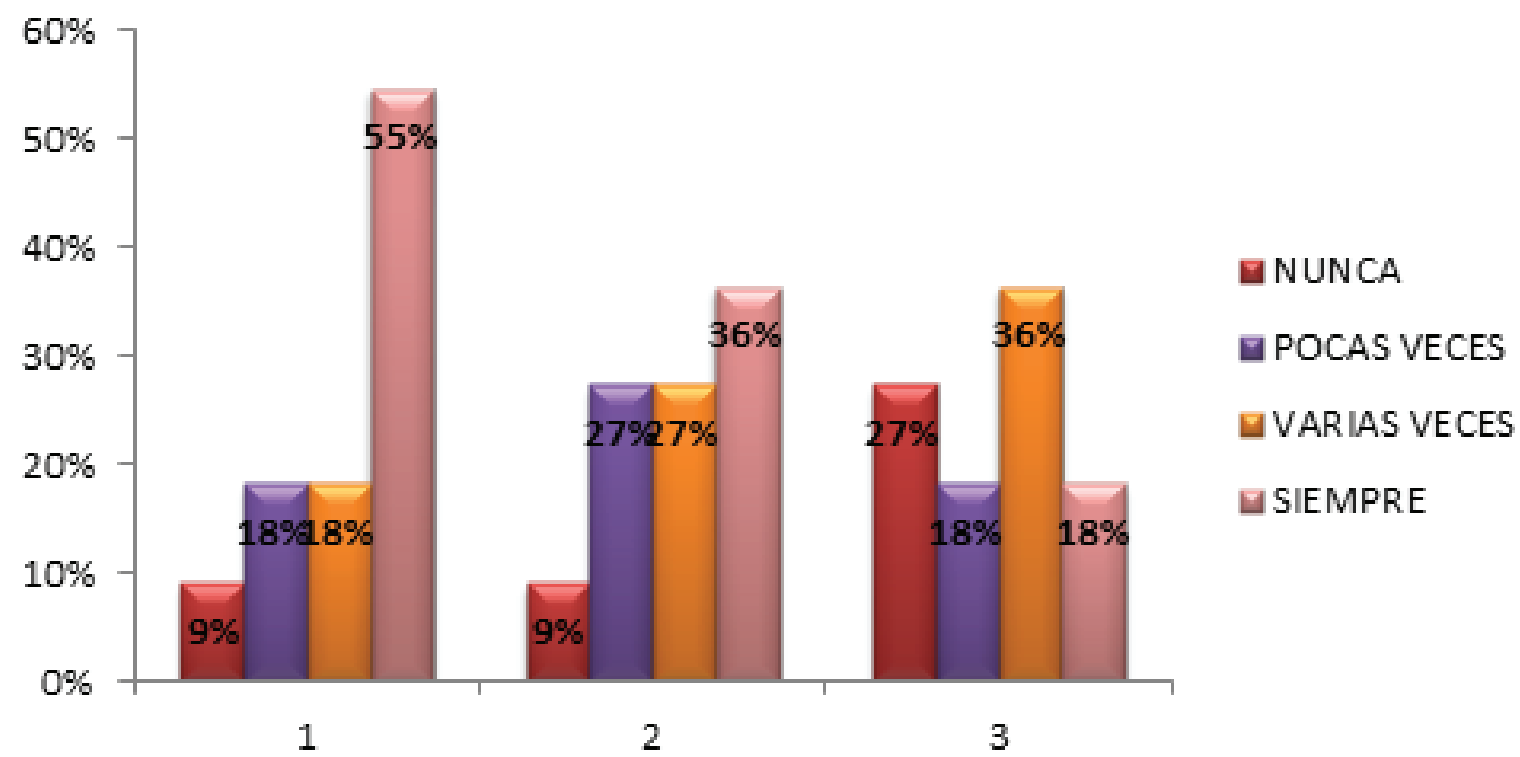

Los números que aparecen al pie del gráfico, corresponden a las tres actividades del programa de actividades por visita que realiza la gestión del centro, los mismos se presentaron en la figura 6.

Como mencionan Castillero et al. (2009), el objetivo principal del programa de actividades por visita que ha de cumplir la dirección de cualquier centro educativo, "consiste en la elaboración de las actividades básicas que debe desarrollar el que va a supervisar al llegar al lugar indicado en un programa de visitas" (p.115). Por tanto, la dirección en su papel supervisor, deberá estar instruido en lo que debe buscar y analizar en cada uno de los puntos de lo observado y en caso de identificar alguna anomalía, debe investigar el porqué de ella, luego explicará y demostrará como corregirla.

Para finalizar, cabe agregar que el programa de desarrollo profesional va dirigido al gestor o gestora del centro, el cual ha de tener conocimiento de todo lo relacionado en materia de inclusión, con la finalidad de que la institución esté abierta a la innovación, a la comunicación y al desarrollo armónico, favoreciendo el proceso de enseñanza y aprendizaje de sus educandos, participando en cursos, asistiendo a seminarios y conferencias, donde se promueva el aprendizaje sobre la temática de la inclusión. En la figura 7, se presentan las actividades del programa de desarrollo profesional. 


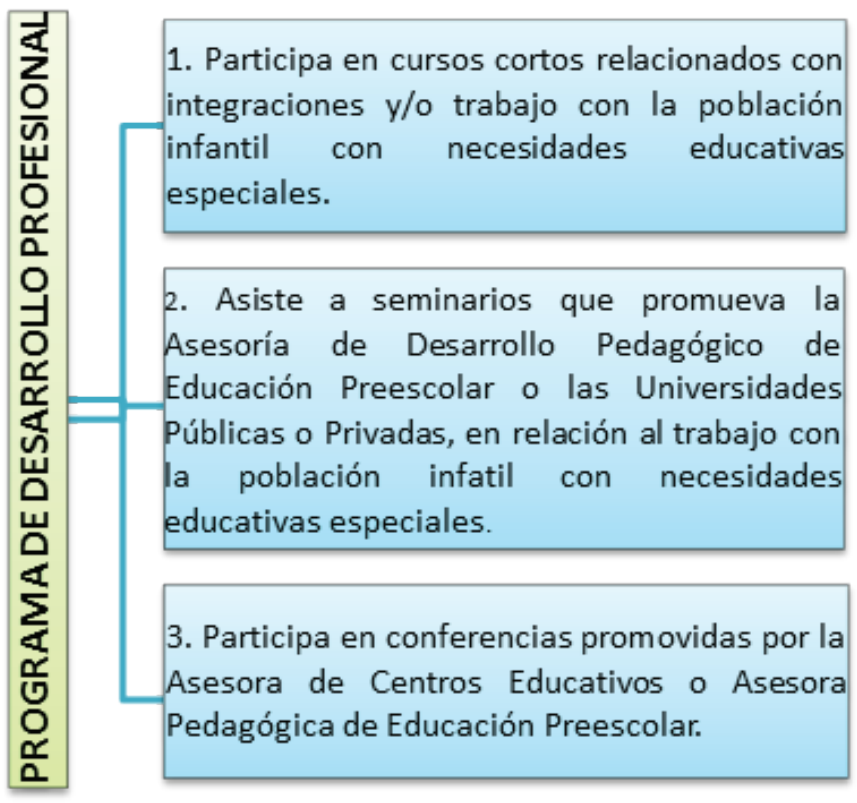

Figura 7. Programa de desarrollo profesional que desarrolla la gestión del centro en el proceso de inclusión de la población infantil con necesidades educativas especiales al grupo regular

Fuente: Gómez, 2012.

La información suministrada por las docentes participantes en el estudio, en relación con el programa de desarrollo profesional dirigido al gestor o gestora del centro, evidencia que debe ser reforzado por tres de las cuatro organizaciones educativas participantes en el estudio, ya que no alcanzaron el $70 \%$ del mínimo establecido por el investigador. Únicamente una gestora lo realiza. 
Gráfico 7. Programa de desarrollo profesional donde participa la gestión del Jardín de Niños Ricardo Jiménez Oreamuno, para favorecerel proceso de inclusión de la población infantil con necesidades educativas especiales, 2012 (Cifras relativas)

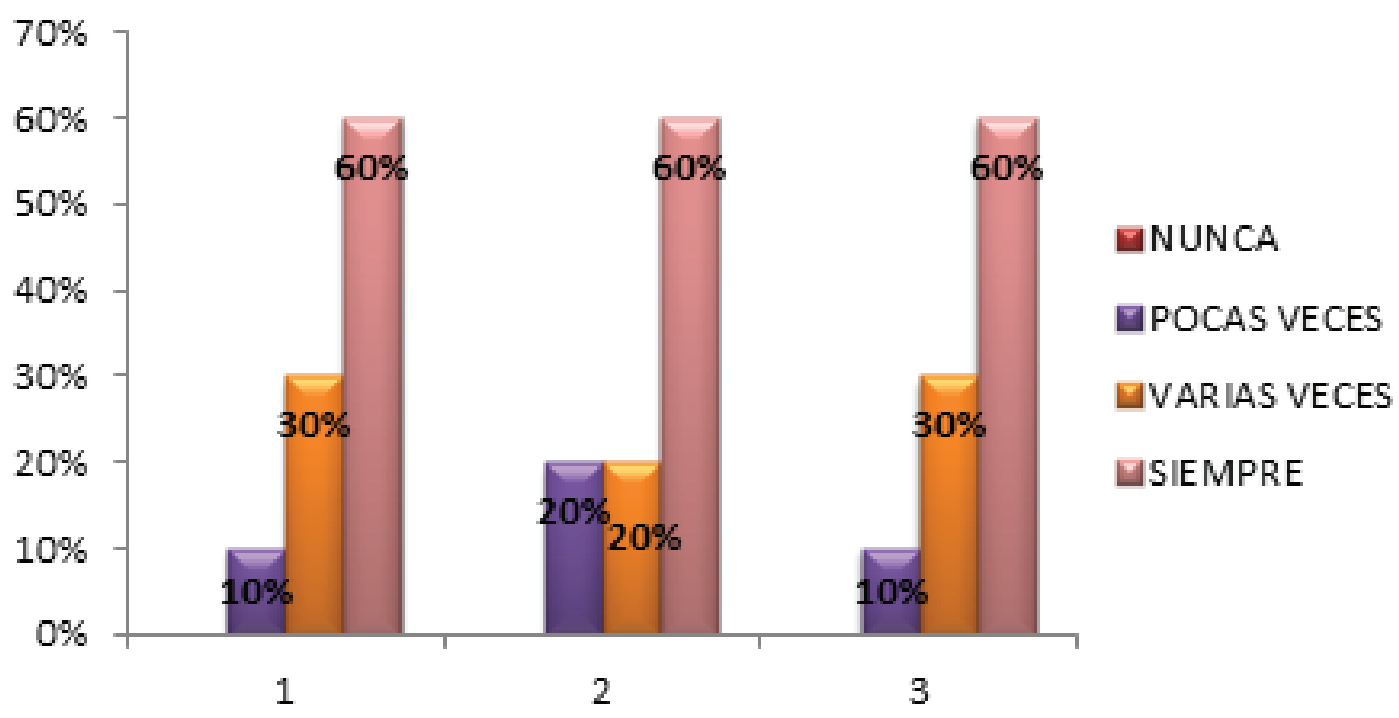

Los números que aparecen al pie del gráfico, corresponden a las tres actividades del programa de desarrollo profesional que desarrolla la gestión del centro en el proceso de inclusión de la población infantil con necesidades educativas especiales, al grupo regular de preescolar. Las mismas se presentaron en la figura 7.

Según se ha visto, los cursos, las conferencias y los semanarios sobre integración o inclusión a los grupos regulares de educación preescolar de la población infantil con necesidades educativas especiales, son importantes para la gestión de cualquier centro, ya que contarán con el insumo para que se lleve a cabo un verdadero proceso de inclusión tomando como referente las necesidades de los educandos, con la finalidad de brindarles una educación acorde con sus capacidades y una educación de calidad.

Cabe agregar que la gestión del centro educativo, es el soporte que guía y orienta a los docentes hacia el logro de los objetivos institucionales y metas que desean alcanzar, cumpliendo con el cometido del derecho a la educación; por tanto, deben participar en un verdadero programa de desarrollo profesional, el cual consiste en buscar, por parte de la gestión del centro, los mecanismos con diversas instancias del MEP, Asesoría Pedagógica de Educación Preescolar, Escuela de Enseñanza Especial, CENAREC, para que impartan cursos de aprovechamiento, de participación, talleres, entre otros, con la finalidad de brindarle a los docentes las herramientas fundamentales para el trabajo en los grupos con la población infantil 
con necesidades educativas especiales, para con ello, cumplir en brindarles una educación de calidad, acorde con sus necesidades e intereses. Logrando así, una educación inclusiva.

\section{Conclusiones}

El estudio permitió examinar desde las estrategias de supervisión utilizadas por la gestión en el proceso de inclusión de la población infantil con necesidades educativas especiales, cómo los criterios de selección de personal, correspondientes a las cualidades personales, sociales e intelectuales y por último, las estrategias de intervención en el proceso de inclusión que tienen que ver con: el programa de visitas, el programa de actividades por visita y programa de desarrollo profesional.

En relación con el primer objetivo, en cuanto a: la búsqueda de las estrategias de supervisión que realiza la gestión del centro educativo, en relación al proceso de inclusión de la población infantil con necesidades educativas especiales, en los grupos regulares de educación preescolar, se obtienen las siguientes conclusiones.

- La gestión de los Jardines de Niños Ascensión Esquivel, Jesús Jiménez y República Francesa, deben reforzar las siete estrategias de supervisión propuestas, ya que no alcanzan el $70 \%$ del mínimo establecido por la investigadora, con la finalidad de que se dé un verdadero proceso de inclusión de la población infantil con necesidades educativas especiales, en los grupos regulares de educación preescolar. Por su parte, la gestión del Jardín de Niños Ricardo Jiménez Oreamuno ha de reforzar las estrategias de supervisión: uno, tres, seis y siete, las cuales tienen que ver con visitas y observaciones a los grupos, con el fin de conocer el trabajo docente con la población infantil con necesidades educativas especiales, la confección de boletines informativos sobre temas de inclusión y la elaboración de cuestionarios para conocer la opinión de padres y madres de familia sobre la labor docente, en ese sentido.

En relación con el segundo objetivo, en cuanto a: los criterios de selección de personal, para la asignación de los docentes de la población infantil con necesidades educativas especiales en los grupos regulares de educación preescolar, los cuales se dividen en cualidades personales, sociales e intelectuales, se obtienen las siguientes conclusiones por criterio e institución.

- Se evidencia que la gestión del Jardín de Niños Ascensión Esquivel, en relación con las cualidades personales, debe reforzar: el dominio de sí mismo; la paciencia y tolerancia; el optimismo ante situaciones adversas; la creación de condiciones idóneas para que se dé un ambiente confortable entre quienes lo rodean; poseer dominio de las actividades propias del trabajo que desempeña; poseer capacidad de organización de su trabajo, de 
manera semanal, quincenal y diaria; respeto por los valores culturales del grupo y mostrar deseos de superación, tanto en el campo personal como profesional.

La cualidad personal a la que la gestión da énfasis es a la importancia de que la docente posea capacidad de organización de su trabajo de manera quincenal, semanal o diaria. La gestión de los Jardines de Niños Jesús Jiménez y Ricardo Jiménez Oreamuno, toman en cuenta, en la selección, las diez cualidades personales propuestas en el estudio. La gestión del Jardín de Niños República Francesa, ha de reforzar las diez cualidades personales, con la finalidad de seleccionar de manera idónea el personal que trabajará con la población infantil con necesidades educativas especiales, debido a que no cumple con el 70\% del mínimo establecido por el investigador.

En relación con las cualidades sociales, no se alcanzó el 70\% como mínimo establecido por el investigador, en la primera, relacionada con el desarrollo de relaciones interpersonales, tanto con los educandos como con padres de familia y encargados y la tercera, que tiene que ver con la buena comunicación entre el personal docente. La segunda cualidad, si está presente en la gestión del Jardín de Niños Ascensión Esquivel, ya que sobrepasó el 70\% como mínimo establecido. La gestión del Jardín de Niños Jesús Jiménez, toma en cuenta a la hora de seleccionar el personal para trabajar con la población infantil con necesidades educativas especiales, las tres cualidades sociales propuestas por el investigador, los mismos alcanzaron un 100\%. La gestión del Jardín de Niños República Francesa, debe fortalecer la cualidad social dos. Las cualidades sociales uno y tres sobrepasaron el 70\%, por su parte el gestor del Jardín de Niños Ricardo Jiménez Oreamuno, debe reforzar la cualidad social dos y la tercera, ya que no alcanzan el 70\% del mínimo establecido, y fortalecer la uno, cualidad presente en la organización.

- La gestión del Jardín de Niños Ascensión Esquivel, es importante que refuerce las cualidades intelectuales: poseer capacidad para aplicar los conocimientos a las situaciones que se presenten al trabajar con la población infantil con necesidades educativas especiales; capacidad de comprensión verbal, para lograr una comunicación paralela; capacidad de análisis y de síntesis; capacidad de percepción en relación con las necesidades y problemas de la población infantil para ser tratados a tiempo; selección y utilización de métodos de enseñanza individual y variada, acorde con las necesidades de la población infantil; conocer y aplicar los métodos de enseñanza individual y variada, acorde con las necesidades de la población infantil; aplicación de estrategias de motivación para mejorar el clima psicológico del grupo, ya que no alcanzan el 70\% del mínimo establecido, con la finalidad de lograr integrar las demás cualidades a la labor del docente, en el proceso de inclusión de la población infantil con necesidades educativas en los grupos regulares. La gestión del Jardín de Niños Jesús Jiménez, toma en cuenta las ocho cualidades intelectuales, permitiendo de ese modo que se le brinde a los educandos una educación inclusiva de calidad. 
La cualidad intelectual que alcanza el porcentaje mayor al 70\% del mínimo establecido, es la dos, por tanto, la gestión del Jardín de Niños República Francesa ha de dar mayor énfasis a las cualidades: uno, tres, cuatro, cinco, seis, siete y ocho, ya que no alcanzan el mínimo establecido por el investigador. La gestión del Jardín de Niños Ricardo Jiménez Oreamuno debe trabajar con el personal docente a su cargo las cualidades intelectuales dos y tres, ya que no alcanzaron el 70\% del mínimo establecido por el investigador, las otras seis cualidades si están presentes en la organización

En relación con tercer objetivo, referente a: las estrategias de intervención en el proceso de inclusión de la población infantil con necesidades educativas especiales, a los grupos regulares de educación preescolar, relacionadas con el programa de visitas, programa de actividades por visitas y programa de desarrollo profesional, se extraen las siguientes conclusiones.

- Como estrategia de su plan, la gestión de los Jardín de Niños Ascensión Esquivel y República Francesa, deben planear tanto las visitas anuales como las mensuales, con la finalidad de secuenciar las acciones que se tomarán en cuenta para que se dé un verdadero proceso de inclusión, teniendo como referente las leyes y reglamentos que en materia de inclusión se han promulgado, ya que no alcanzaron el 70\% del mínimo establecido por el investigador. Por su parte, la gestión de los Jardines de Niños Jesús Jiménezy Ricardo Jiménez Oreamuno, cumple con la organización tanto con las visitas anuales como mensuales.

- Las tres actividades, del programa de actividades por visita, deben ser reforzadas por la gestión de los Jardines de Niños Ascensión Esquivel y República Francesa, porque no alcanzan el 70\% del mínimo establecido,correspondientes a: brindar a los y las docentes recomendacionesverbales o por escrito del desarrollo de su trabajo con la población infantil con necesidades educativas especiales; recomendar algunos cursos de modificación de conducta, adecuaciones, integraciones, supervisión personal, valores, autoestima, entre otros, al personal docente a su cargo; implemantar charlas o seminarios dirigidos a la integración de la población infantil con necesidades educativas especiales y su trabajo en el grupo. En el Jardín de Niños Jesús Jiménez, se evidencia que las tres actividades están presentes en la organización, ya que sobrepasaron el 70\% del mínimo establecido por el investigador.

Por su parte, la gestión del Jardín de Niños Ricardo Jiménez Oreamuno debe reforzar la dos referente con recomendar algunos cursos de modificación de conducta, adecuaciones, integraciones, supervisión personal, valores, autoestima, entre otros, al personal docente a su cargo y la tres, implemantar charlas o seminarios dirigidos a la integración de la población infantil con necesidades educativas especiales y su trabajo en el grupo. ya que no alcanzaron el 70\% del mínimo establecido por el investigador, 
esto con la finalidad de que se dé un verdadero proceso de inclusión en la organización que lidera. La actividad uno, si está presente en el centro.

- En relación con el programa de desarrollo profesional, la gestión de los Jardines de Niños Ascensión Esquivel y Ricardo Jiménez Oreamuno, han de reforzar las tres actividades, debido a que no están presentes en la organización, ya que no alcanzan el 70\% del mínimo establecido. Las actividades de desarrollo profesional son relevantes, en tanto le brindan al director las herramientas para trabajar con su personal y observar el trabajo que estos desempeñan cuando cuentan con población infantil con necesidades educativas en sus grupos.

Se evidencia que la gestión del Jardín de Niños Jesús Jiménez, participa de un verdadero programa de desarrollo profesional al asistir a cursos, seminarios y conferencias donde se promueva el tema de la inclusión de la población infantil con necesidades educativas en los grupos regulares de preescolar, esto porque las tres actividades del programa de desarrollo profesional sobrepasan el 70\% del mínimo establecido por el investigador.

La gestión del Jardín de Niños República Francesa debe reforzar la uno, correspondiente a la participación en cursos cortos relacionados con integraciones y/o trabajo con la población infantil con necesidades educativas y la tres, participa en conferencias promovidas por la Asesora de Centros Educativos o Asesora Pedagógica de Educación Preescolar, esto con la finalidad de alcanzar un mayor grado de actualización en temas de inclusión y de integración, asistiendo a cursos, seminarios y conferencias, generando nuevos conocimientos, nuevas estrategias de trabajo, para así trabajar en conjunto con los docentes las integraciones y en especial la inclusión de la población infantil con necesidades educativas especiales en los grupos regulares.

La educación como pilar fundamental de la sociedad costarricense requiere de gestores educativos comprometidos, responsables de hacerla efectiva ofreciendo una educación de calidad, acorde con las demandas sociales, las cuales deben responder a las necesidades de igualdad y equidad entre las personas.

Por tanto, le corresponde desarrollar diversas estrategias y actividades tendientes a brindar en las organizaciones una educación inclusiva, destacando el derecho humano básico, de todos y no de unos pocos, para el desarrollo individual y social que promueve la paz, la libertad y la justicia, en contraposición con la exclusión, la discriminación y la ignorancia.

En sí, se necesita de gestores de la educación anuentes al cambio, a la innovación, al desarrollo de competencias, habilidades y destrezas, que guíen y orienten en todo momento a su personal, hacia el logro de los objetivos de una educación inclusiva de calidad, de manera 
responsable y acorde con los cambios que se vienen dando en materia de inclusión.

De acuerdo con los razonamientos que se han venido realizando, es de suma importancia que la gestión cumpla tanto con la demanda internacional de una educación de calidad y del derecho que la población infantil tiene, una vez que está inmerso en el sistema educativo regular, independientemente de sus capacidades, así como el respeto a la diversidad.

\section{Propuesta de intervención}

Mediante el estudio, se logró identificar la necesidad por parte de la gestión de los centros educativos participantes, en contar con diversas estrategias y actividades para lograr una educación inclusiva de calidad, donde el gestor y la gestora, en su rol de supervisor, reconozca las necesidades instituciones y los plasme en el plan operacional para cumplir con el derecho que la población infantil con necesidades educativas poseen.

Desde el punto de vista de la administración de la educación, la propuesta adquiere relevancia, ya que el rol de la administración de la educación en la gestión de un proceso de inclusión requiere de conocimientos, habilidades, destrezas, competencias, cultura colaborativa, pensamiento creativo, acción comprometida y en especial de una actitud positiva hacia el personal, con el fin de motivarlos hacia el logro de las metas que en materia de inclusión se proponga el centro educativo.

La propuesta consiste en el diseño de cuatro módulos, con los cuales se pretende ofrecer a la administración de la educación de los cuatro jardines de preescolar participantes en el estudio, diversas estrategias de intervención para lograr un verdadero proceso de inclusión y de esa manera cumplir en primera instancia con el derecho que tiene la población infantil con necesidades educativas a una educación de calidad y, en segunda instancia, cumplir con las directrices emanadas por la UNESCO y la Organización de las Naciones Unidas (ONU) en relación con la inclusión.

\section{Objetivo General.}

- Diseñar un proyecto de concienciación sobre inclusión, cualidades de selección de personal, estrategias de supervisión y estrategias de intervención, en relación con el proceso de inclusión de la población infantil con necesidades educativas especiales, en los grupos de educación preescolar, para ser aplicado por la gestión de los Jardines de Niños Ascensión Esquivel, Jesús Jiménez, República Francesa y Ricardo Jiménez Oreamuno, pertenecientes a los circuitos escolares 04, 05 y 06, de la Dirección Regional de Educación de Cartago. 


\section{Objetivos Específicos.}

- Concienciar a los directores y docentes de los centros educativos en estudio, en cuanto a la importancia de la inclusión de la población infantil con necesidades educativas especiales desde el preescolar.

- Valorar diversos criterios de selección de personal, a la hora de asignar los docentes para atender a la población infantil con necesidades educativas especiales, en los grupos de educación preescolar.

- Determinar diversas estrategias de supervisión en el proceso de inclusión de la población infantil con necesidades educativas especiales en los grupos regulares de educación preescolar.

- Establecer diversas estrategias de intervención que sirvan a la gestión para implementar en el proceso de inclusión de la población infantil con necesidades educativas especiales en los grupos regulares de educación preescolar.

\section{Plan de acción.}

Para el desarrollo del plan de acción, se proponen los siguientes módulos participativos:

MÓDULO I: Concienciación sobre la importancia de la inclusión de la población infantil con necesidades educativas especiales, desde el preescolar.

MÓDULO II: Cualidades de selección de personal, que ha de tener en cuenta el gestor o la gestora del centro, para desarrollar en quienes laboran de la población infantil con necesidades educativas especiales, en los grupos de preescolar.

MÓDULO III: Estrategias de intervención a implementar por la gestión del centro, en el proceso de inclusión de la población infantil con necesidades educativas especiales, en los grupos de preescolar

MÓDULO IV: Estrategias de supervisión a utilizar por la gestión del centro, en relación al proceso de inclusión de la población infantil con necesidades educativas especiales, en los grupos de preescolar. 


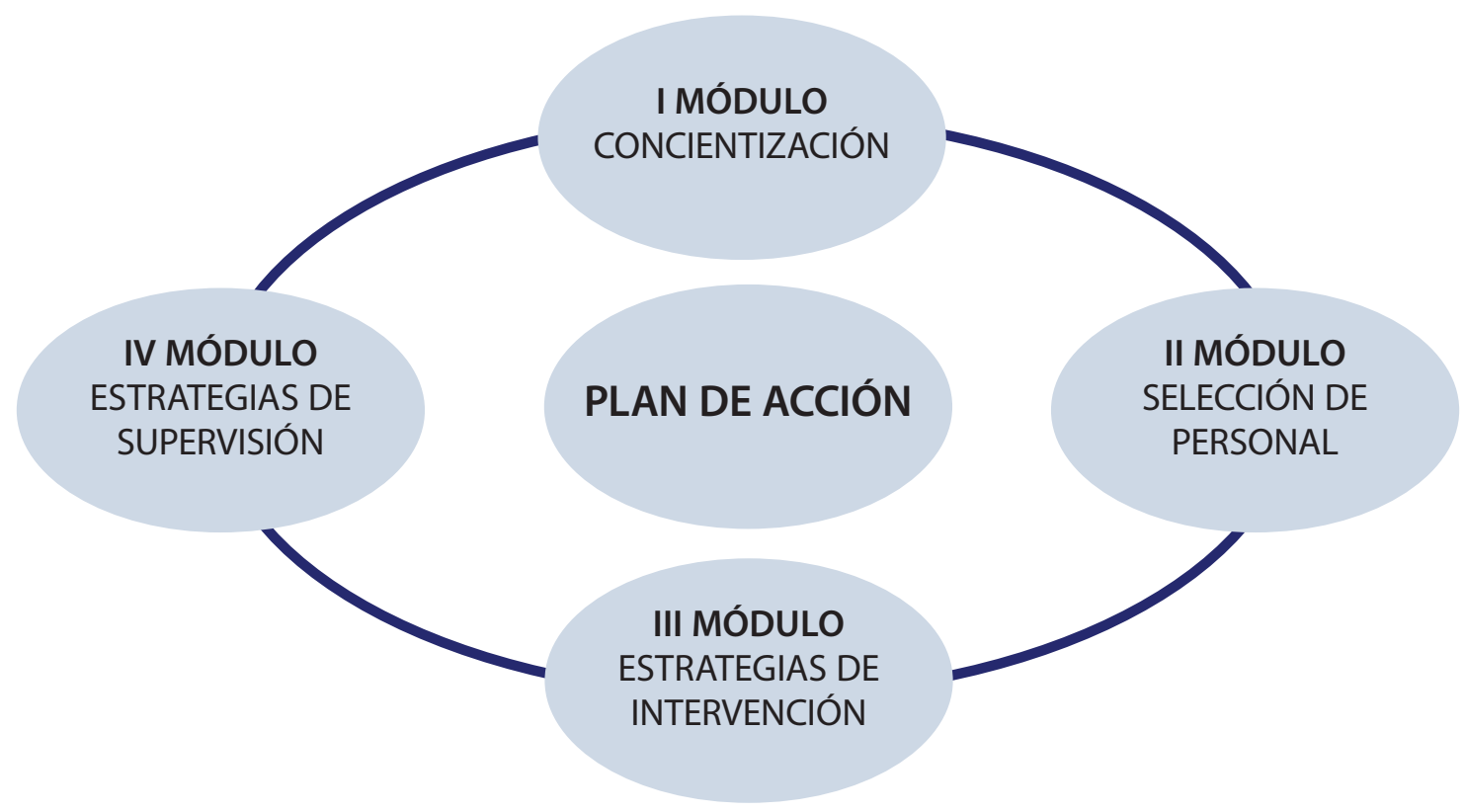

Figura 8. Módulos participativos por desarrollar en el plan de acción

Nota: Gómez, 2012.

Los mismos van acorde con las directrices emanadas de las convenciones, conferencias, declaraciones reuniones y jornadas que, organismos como la UNESCO y la Organización de Estados Americanos (OEA), han realizado a los diversos Estados para ejecutar en la instituciones educativas, con el objetivo de que se den verdaderos procesos de inclusión con la población infantil con necesidades educativas especiales, para el logro de su incorporación a la vida laboral y social de cada país.

Los cuatro módulos a desarrollar son participativos, conformados por sesiones de capacitación, las cuales pretenden fomentar vínculos entre la gestión del centro y el cuerpo docente, así como concienciar a los directores y directoras de realizar un diagnóstico de lo que se ha venido trabajando en materia de inclusión y lo que hace falta, para brindarle a la población infantil con necesidades educativas especiales, una educación inclusiva de calidad y hacer partícipes al cuerpo docente de las innovaciones, cambios y modificaciones que se deben realizar para lograr una inclusión acorde con las características y necesidades de los educandos. 


\section{Referencias}

Arroyo, J. A. (2011). Gestión estratégica de las organizaciones. San José, Costa Rica: Editorial UCR.

Asamblea Legislativa, C.R. (1996). Ley de Igualdad de Oportunidades. Ley 7600. Recuperado en: http://www.bcn.cl/carpeta_temas/temas_portada.2005-10-24.2908836766/pdf/ Ley7600_costa\%20rica.pdf

Ávila, A.L. y Esquivel, V.E. (2009). Educación inclusiva en nuestras aulas. Vol. 37. Colección Pedagógica Formación Inicial de Docentes Centroamericanos de Educación Primaria o Básica San José, Costa Rica: CECC/SICA.

Castillero, A. B.; Díaz, J.D.; Morales, D.F. y Pino de Ochoa, I. (2009). Gestión y supervisión en el centro de educación básica. Vol. 36. Colección Pedagógica Formación Inicial de Docentes Centroamericanos de Educación Primaria o Básica San José, Costa Rica: CECC/SICA.

Centro Nacional de Recursos para la Inclusión Educativa (CENAREC). (2004). Conferencias magistrales: ciclos anuales 2002 y 2003 del Centro Nacional de Recursos para la Inclusión Educativa. Fundación Mundo de Oportunidades. San José, Costa Rica: EDITORAMA.

Contreras, M. (2005). Aprender a desaprender: apuntes en la búsqueda de un aprendizaje transformativo para la capacitación de directores de Escuela. Instituto Interamericano para el Desarrollo Social (INDES). Recuperado en: https://docs.google.com/document/ d/1ODqaNKVsCvDN2PL1xjyFEPE-Bb 2P 3BQwdKzU5GKGl/edit?hl=es

Fondo de las Naciones Unidas para la Infancia (UNICEF). (1989). Convención de los Derechos del Niño. Recuperado en: http://www2.ohchr.org/spanish/law/crc.htm

Garbanzo, G. M. y Orozco, V.H. (2007). Desafíos del Sistema Educativo Costarricense: Un nuevo paradigma de la administración de la educación. Revista Educación, 31(2), pp. 95-110. Recuperado en: http://www.latindex.ucr.ac.cr/educacion-31-2/06-GARBANZO.pdf

García, N.; Rojas, M. y Campos, N. (2002). La administración escolar para el cambio y el mejoramiento de las instituciones educativas. San José, Costa Rica: Editorial UCR.

Gento, S. (1999). Gestión y supervisión de centros educativos. San José, Costa Rica: EUNED.

Hernández, S.; Fernández, S. y Baptista, L. (2003). Metodología de la Investigación. México: MC Graw Hill Interamericana. 
Jiménez, A.L. (1990). Perfil profesiográfico del maestro de educación preescolar. (Tesis para optar por el grado de Licenciatura en Psicología). Universidad de Costa Rica. Ciudad Universitaria Rodrigo Facio. San José, Costa Rica.

Lerma, H.D. (2004). Metodología de la investigación: Propuesta, anteproyecto y proyecto. Colombia: Editorial Ecoe Ediciones.

Meléndez, L. (2005). La educación especial en Costa Rica. Fundamentos y evolución. San José, Costa Rica: EUNED.

Ministerio de Educación Pública (MEP). (1999). Programa de Estudios del Ciclo de Transición de la Educación Preescolar. San José, Costa Rica: Autor.

Richmond, V. (2009). El camino de la inclusión de personas con necesidades educativas especiales en Costa Rica: aportes para la discusión. Revista Educación, 33(2). Recuperado en: http://www.latindex.ucr.ac.cr/edu009-05.php

Pozner, P.; Ravela, P. y Fernández, T. (2000). Diez módulos destinados a los responsables de los procesos de transformación educativa. Buenos Aires, Argentina: UNESCO-IIPE. 